\title{
Large eddy simulation of ship tracks in the collapsed marine boundary layer: a case study from the Monterey area ship track experiment
}

\author{
A. H. Berner, C. S. Bretherton, and R. Wood \\ Department of Atmospheric Science, University of Washington, Seattle, Washington, USA \\ Correspondence to: A. H. Berner (andy.berner@gmail.com) \\ Received: 30 August 2014 - Published in Atmos. Chem. Phys. Discuss.: 22 September 2014 \\ Revised: 3 April 2015 - Accepted: 15 April 2015 - Published: 27 May 2015
}

\begin{abstract}
For the first time, a large eddy simulation (LES) coupled to a bulk aerosol scheme is used to simulate an aircraft-sampled ship track. The track was formed by the M/V Sanko Peace on 13 June 1994 in a shallow drizzling boundary layer with high winds but very low background aerosol concentrations $\left(10 \mathrm{~cm}^{-3}\right)$. A Lagrangian framework is used to simulate the evolution of a short segment of track as it is advected away from the ship for $8 \mathrm{~h}$ (a downwind distance exceeding $570 \mathrm{~km}$ ).

Using aircraft observations for initialization, good agreement is obtained between the simulated and observed features of the ambient boundary layer outside the track, including the organization of the cloud into mesoscale rolls. After $8 \mathrm{~h}$, a line of aerosol is injected to start the ship track. The simulation successfully reproduces the significant albedo enhancement and suppression of drizzle observed within the track. The aerosol concentration within the track dilutes as it broadens due to turbulent mixing. A sensitivity study shows the broadening rate strongly depends on the alignment between the track and the wind-aligned boundary layer rolls, as satellite images of ship tracks suggest. Entrainment is enhanced within the simulated track, but the observed $100 \mathrm{~m}$ elevation of the ship track above the surrounding layer is not simulated, possibly because the LES quickly sharpens the rather weak observed inversion. Liquid water path within the simulated track increases with time even as the ambient liquid water path is decreasing. The albedo increase in the track from liquid water and cloud fraction enhancement (second indirect effect) eventually exceeds that from cloud droplet number increases (first indirect or Twomey effect). In a sensitivity study with a higher initial ambient aerosol concentration, stronger ship track aerosol source, and much
\end{abstract}

weaker drizzle, there is less liquid water inside the track than outside for several hours downwind, consistent with satellite estimates for such situations. In that case, the Twomey effect dominates throughout, although, as seen in satellite images, the albedo enhancement of the track is much smaller.

\section{Introduction}

Ship tracks are one of the most striking examples of anthropogenic impact on the atmosphere. Conover (1966) first identified "anomalous cloud lines" over the ocean in early visiblewavelength satellite imagery. He correctly hypothesized that cloud condensation nuclei $(\mathrm{CCN})$ forming in plumes of ship emissions could perturb marine boundary layer (MBL) clouds and increase their reflectance. Twenty years later, Coakley et al. (1987) found that many ship tracks without an obvious visible-wavelength albedo signature could still be detected using near infrared (IR) satellite imagery, because of the sensitivity of near-IR radiative transfer to the cloud droplet size spectrum. Later work (Coakley and Walsh, 2002; Chen et al., 2012; Christensen and Stephens, 2012) deduced liquid water path (LWP) changes between ship tracks and the surrounding environment, showing that tracks could also exhibit LWP decreases, not just LWP increases.

The effects of aerosols on cloud radiative properties are often partitioned into the first (Twomey, 1977) and second (Albrecht, 1989; Liou and Ou, 1989; Stevens and Feingold, 2009) aerosol indirect effects. The first indirect effect is the change in net top-of-atmosphere (TOA) shortwave radiation (positive downward) resulting from a change in cloud droplet number when holding other properties constant, while the 
second aerosol indirect effect is the additional net TOA shortwave change due to impacts on macrophysical cloud properties like water content, precipitation, turbulence and cloud lifetime that result from microphysical feedbacks. Ship tracks owe their existence to aerosol-cloud interactions, and thus provide an excellent means to study them.

The first in situ measurements of ship tracks were made with an aircraft by Radke et al. (1989) in a solid stratocumulus deck, and from a ship by Hindman et al. (1994) under cleaner conditions with a lower background cloud fraction. Ackerman et al. (1995) used these observations as the basis for a modeling study. They classified ship tracks as "Type 1", with an obvious albedo enhancement in visible satellite imagery, or "Type 2", evident only in near-IR $(3.7 \mu \mathrm{m})$ images. They employed a one-dimensional column model with a turbulence closure, which is a computationally efficient way to focus on aerosol-cloud interaction but has limited scope, since it cannot simulate horizontal dispersion, the circulation structure of a ship track, or horizontal covariations between turbulent eddies and cloud throughout the boundary layer. In their simulations of the Type 1 track (based on the observations of Hindman et al., 1994), LWP and cloud droplet number concentration $N_{\mathrm{d}}$ were elevated above the control run for the entirety of the simulation (a positive first and second aerosol indirect effect), yielding a substantial increase in albedo (greater than $50 \%$ ). They also simulated a Type 2 ship track (based on the observations of Radke et al., 1989) and found a daytime LWP reduction (negative second aerosol indirect effect), due to enhanced subcloud drizzle evaporation giving a less well-mixed boundary layer. These results compared reasonably well to the limited available observations.

Community interest in aerosol cloud interactions as exemplified by ship tracks led to the Monterey Area Ship Track experiment (MAST; Durkee et al., 2000a) in 1994. Aircraft surveys by multiple platforms provided in situ measurements of many ship tracks and their contrast with the ambient boundary-layer conditions. During research flight A338 on 13 June 1994, the United Kingdom Meteorological Office (UKMO) Meteorological Research Flight (MRF) C-130 sampled a Type 1 ship track generated in a collapsed boundary layer by the M/V Sanko Peace. Arguably, this is one of the best-sampled Type 1 ship tracks documented in the scientific literature. An interesting and unusual feature of the case was the observation that the ship track appeared elevated as much as $100 \mathrm{~m}$ above surrounding cloud tops. Taylor and Ackerman (1999) summarized the extensive set of aircraft measurements and performed comparison simulations using their 1-D column model. They obtained good agreement with the relative albedo enhancement seen in the observations, with comparable LWP, effective radius $r_{\mathrm{e}}$, and $N_{\mathrm{d}}$ in both the track and background environment, but again their modeling framework was not designed to simulate the horizontal structure of the track and its downstream evolution.

An obvious step up in modeling sophistication would be to use a large eddy simulation (LES) coupled to an aerosol physics model. Surprisingly few LES of real ship tracks have been attempted. The studies of Wang and Feingold (2009) and Wang et al. (2011) examined idealized ship tracks in an $800 \mathrm{~m}$ deep boundary layer, at the upper limit of the 300$800 \mathrm{~m}$ MBL depth range typical of the MAST cases (Durkee et al., 2000b). Their simulated tracks showed regions of albedo reduction around the ship track that in the area mean largely canceled out the enhanced in-track albedo, yielding a very weak total aerosol indirect effect. However, they had no observational constraint, a limitation that the present study aims to address.

We revisit the Sanko Peace case using an LES model with a coupled bulk aerosol model developed by Berner et al. (2013). The case provides an opportunity to test the skill of this model, which combines a sophisticated representation of turbulence with an intermediate-complexity description of the aerosol and its interaction with cloud processes, against observations, and more generally test whether this modeling framework can significantly add to one-dimensional turbulence closure methods. Our work is organized as follows: further detail on the observations and previous modeling work is given in Sect. 2. Model formulation is described in Sect. 3 and forcing and initialization detailed in Sect. 4. The simulations are discussed in Sect. 5, including sensitivity studies on track orientation and background aerosol concentration, and a simplified model for cloud albedo (Platnick and Twomey, 1994; Brenguier et al., 2000) is used to partition the simulated albedo enhancement into contributions from the first and second indirect effects. In Sect. 6, we briefly discuss the interpretation of the simulations in the context of cloudaerosol regimes (Rosenfeld et al., 2006; Berner et al., 2013), followed by conclusions in Sect. 7.

\section{The Sanko Peace case study}

Our case study description draws from the work of Taylor and Ackerman (1999), additional analysis of the flight data (kindly provided by Simon Osborne of the UKMO), and satellite imagery for the case. For details of the aircraft instrumentation and sampling strategy, the interested reader is referred to the Taylor and Ackerman (1999) study. The boundary layer was quite shallow, with cloud tops at $300 \mathrm{~m}$ and very clean background aerosol concentrations of $10 \mathrm{~cm}^{-3}$. $\mathrm{CCN}$ and condensation nuclei $(\mathrm{CN})$ concentrations were negligible above the inversion up to a kilometer in depth. MBL wind was moderately strong, with aircraft observed speeds of $\sim 14 \mathrm{~m} \mathrm{~s}^{-1}$ (150 $\mathrm{m}$ altitude) from the north-northwest, driving coherent roll structures within the boundary layer (for a review of boundary layer roll vortices, see Etling and Brown, 1993). We obtained Geostationary Operational Environmental Satellite (GOES) visible imagery at the time of aircraft sampling, which is shown in Fig. 1. The roll organization within the boundary layer is readily apparent; unfortunately, high cirrus cloud obscured the boundary-layer clouds near 


\section{UTC, June 13, 1994}
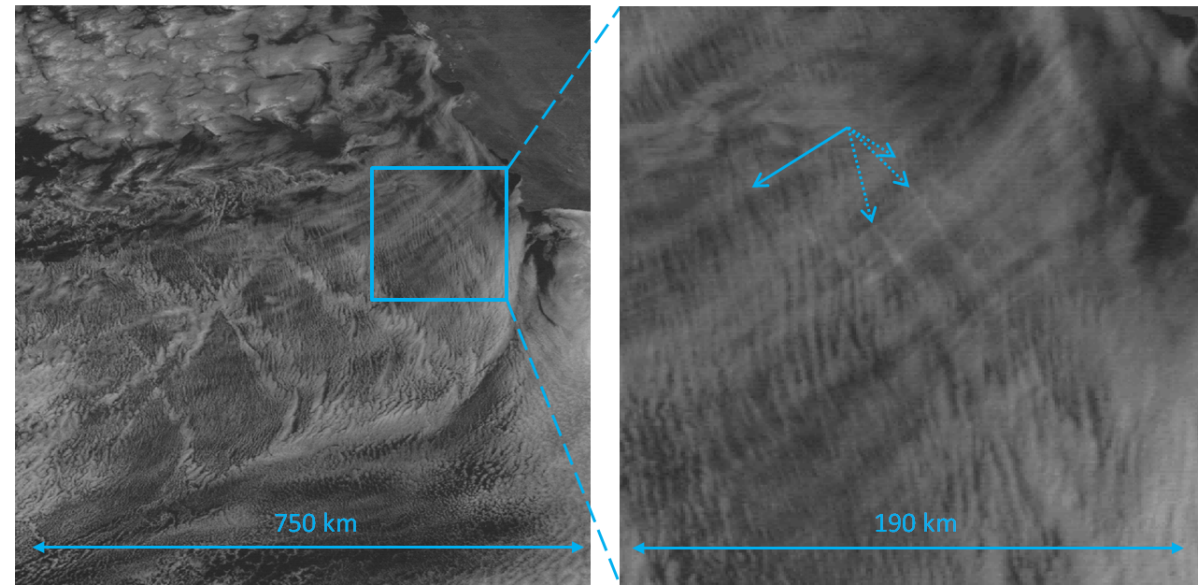

Figure 1. GOES satellite imagery of the eastern Pacific near California at 20:13 UTC on 13 July 1994. A number of ship tracks are clearly visible well off shore. The right panel gives an enlarged view of clouds to the southwest of Monterey; despite cirrus obscuring the view, several tracks are apparent, indicated with arrows. The solid arrow marks the estimated location of the Sanko Peace at the time of the image.

the coast, making it difficult to discern the track, despite a $35 \%$ increase in peak albedo measured by the C-130's multichannel radiometer. The right-hand panel gives an enlarged view of the region near Monterey, and the heads of several faint tracks mentioned in the flight notes are identified with arrows. A solid arrow marks the estimated location of the Sanko Peace, established based on image time and GPS coordinates from the aircraft.

Figure 2 shows an aircraft profile of the environmental wind, liquid water content $q_{1}$, total water $q_{\mathrm{t}}$, cloud droplet concentration $N_{\mathrm{d}}$ (in cloud) and unactivated aerosol concentration $N_{\text {ad }}$ (above cloud; for instrumentation details, see Taylor and Ackerman, 1999), and absolute temperature $T_{\mathrm{abs}}$ (black curves), with overlaid geostrophic wind forcing and idealized initial profiles (blue curves, discussed below in Sect. 4). The inversion structure is quite distinctive, with three nearly isothermal layers, each $\sim 100 \mathrm{~m}$ in depth, separated by $2-3 \mathrm{~K}$ inversions. These layers are all quite moist, with $q_{\mathrm{t}}$ values of $9.25-10 \mathrm{~g} \mathrm{~kg}^{-1}$, nearly identical to the wellmixed layer below. While $N_{\mathrm{d}}$ in the cloud varies between $25-30 \mathrm{~cm}^{-3}$, the air in the $100 \mathrm{~m}$ layer above is essentially pristine, with negligible $N_{\mathrm{ad}}$, and only small concentrations above up to $1 \mathrm{~km}\left(10-30 \mathrm{~cm}^{-3}\right.$, of which a large portion is likely at the smaller end of the size spectrum). This structure could reflect differential advection in layers above the inversion base. It is also suggestive of the result of an aerosolcloud-precipitation feedback-induced collapse of a deeper boundary layer (Ackerman et al., 1993), in which the secondary inversions mark the subsided locations of previous stratocumulus layers which became too optically thin to drive sufficient turbulence to sustain themselves.

Taylor and Ackerman (1999) reported that the ship track rapidly deepened by $100 \mathrm{~m}$ above the surrounding back- ground cloud in less than an hour of downstream development. This rapid deepening may have been partially enabled by the weak cloud-top inversion, but their simulation, which idealized the observed profile, did not produce nearly as much deepening as was observed. Recent remote sensing studies have shown deepening of Type 1 ship tracks to be relatively common (Christensen and Stephens, 2011), but almost no other in situ profiles of the environments that support such deepening are available.

\section{Model formulation}

In the present work, simulations are performed using the System for Atmospheric Modeling (SAM) version 6.9 (Khairoutdinov and Randall, 2003). SAM uses a dynamical core formulated on the anelastic approximation to the Navier Stokes equations to represent fluid motion resolved on the grid. The effects of subgrid turbulence are handled using the 1.5 order turbulent closure model of Deardorff (1980). Scalar advection is performed using the piecewise parabolic method of Blossey and Durran (2008). Coriolis force is included using an $f$ plane approximation, with the Coriolis parameter specified appropriately for the latitude of the case considered. Liquid static energy, $s_{1}=c_{p} T+g z-L q_{1}$, is the conserved thermodynamic variable, as the ice phase is not present in the warm rain cases under consideration. Here $c_{p}$ is the isobaric heat capacity of air, $g$ is gravity, $z$ is height, $L$ is the latent heat of vaporization, and the liquid water mass mixing ratio $q_{1}$ is the sum of cloud water (drops smaller than 25 micron radius) $q_{\mathrm{c}}$ and rain water (drops larger than 25 micron radius) $q_{\mathrm{r}}$. Water vapor $q_{\mathrm{v}}$ is advected separately, and condensation is calculated by saturation adjustment. Surface fluxes are calculated in each grid from Monin-Obukhov theory. 

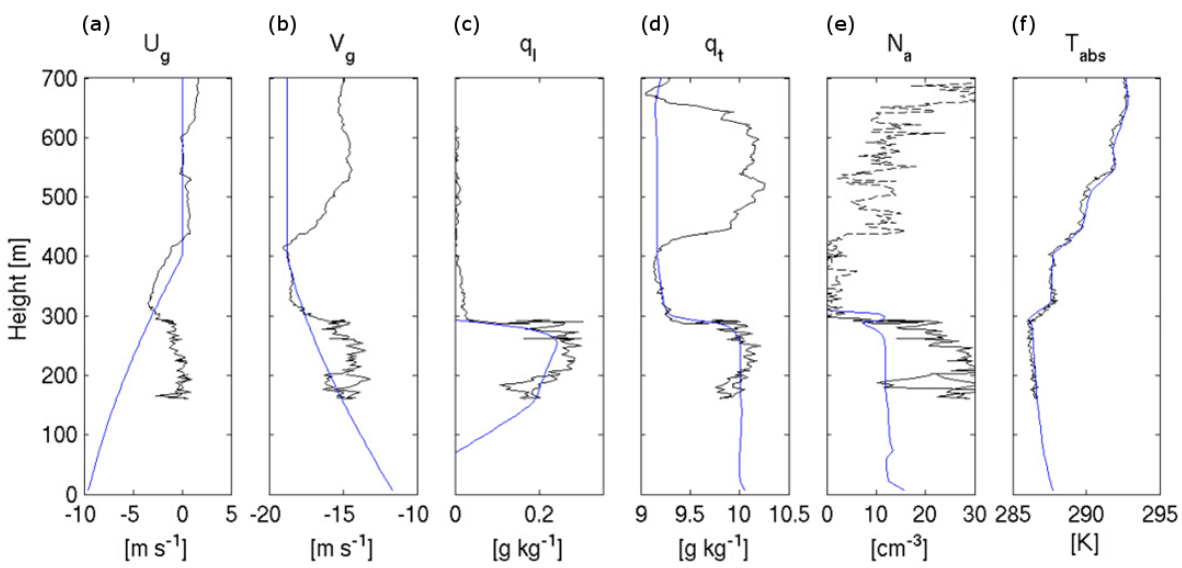

Figure 2. Background profiles of the wind components $u$ and $v$, liquid water mixing ratio $q_{1}$, total water mixing ratio $q_{\mathrm{t}}$, absolute temperature $T_{\mathrm{abs}}$, and total aerosol number concentration $N_{\mathrm{a}}$ (the sum of cloud droplet number concentration $N_{\mathrm{d}}$, rain droplet number concentration $N_{\mathrm{r}}$, and interstitial aerosol number concentration $N_{\text {ad }}$ ) observed by the MRF C-130 prior to sampling the Sanko Peace ship track (black curves). Overlaid are profiles of the forced geostrophic wind components $U_{\mathrm{g}}$ and $V_{\mathrm{g}}$, as well as the initial profiles of $q_{\mathrm{t}}$ and $T$ (blue curves).

Microphysical tendencies are calculated using the twomoment Morrison scheme (Morrison and Grabowski, 2008; Morrison et al., 2005) with the precipitation parameterization of Khairoutdinov and Kogan (2000). A number of modifications have been made, including the use a lookup table for cloud droplet sedimentation and raindrop fall speeds, rain evaporation, and the shape parameter for the gamma rain distribution.

A simple bulk aerosol scheme (described in Berner et al., 2013) has been coupled to the microphysics. It predicts mass and number for a single accumulation mode with a log-normal size distribution of aerosol number that has an assumed geometrical standard deviation $\sigma_{\mathrm{g}}=1$.6. This approach requires a minimal number of additional advected scalars while allowing for the inclusion of realistic aerosolcloud-precipitation feedbacks; a limitation of this method is that it does not represent the growth of a separate Aitken mode of smaller particles to $\mathrm{CCN}$-active sizes. Processes affecting aerosol in the scheme include activation, autoconversion, accretion, evaporation, scavenging of interstitial unactivated aerosol by cloud and rain, and fallout to the surface. A surface source based on the sea-salt parameterization of Clarke et al. (2006) is included. Radiation calculations are performed using the Rapid Radiative Transfer Model (RRTM; Mlawer et al., 1997), which in our implementation utilizes a combined cloud-drizzle $r_{\mathrm{e}}$ diagnosed from the 3-D microphysical fields. Unactivated aerosol is not included in the radiation calculation.

\section{Model domain, resolution, and boundary conditions}

Simulations in this paper are run on a $51.2 \mathrm{~km} \times 12.8 \mathrm{~km}$ domain with $50 \mathrm{~m}$ horizontal resolution. Vertical spacing is $15 \mathrm{~m}$ near the surface, shrinking to $5 \mathrm{~m}$ in a layer from 70 to $500 \mathrm{~m}$ in depth, and then stretching continuously to the do- main top at $29 \mathrm{~km}$ (necessary to avoid reengineering the implementation of the radiative transfer scheme in the model). The time step is $0.5 \mathrm{~s}$. Boundaries are doubly periodic in the horizontal, with a sponge layer in the upper portion of the domain to absorb gravity waves and prevent spurious reflections from the rigid lid.

\section{Initialization and forcing}

The goal of our model initialization and forcing is to produce a boundary layer qualitatively and quantitatively similar to the background environment described by Taylor and Ackerman (1999). As the evolution of the boundary layer prior to sampling and large scale meteorological forcings remain uncertain, the final initial values and forcings were empirically chosen using pilot simulations to improve the quantitative match between observations and the hour- 8 boundary layer statistics.

\subsection{Temperature, moisture, and wind}

The horizontal coordinates $x$ and $y$ are aligned such that the boundary-layer mean wind, which is from $30^{\circ}$ west of north, lies along the $-y$ direction. $u$ and $v$ denote the wind components in the $x$ and $y$ directions. The blue curves in Fig. 2 show the geostrophic wind profiles $U_{\mathrm{g}}$ and $V_{\mathrm{g}}$ used to force the model, which were chosen to approximately produce the observed wind profiles, as well as the smoothed $q_{\mathrm{t}}$, total aerosol concentration $N_{\mathrm{a}}$, and $T$ profiles used for model initialization. The initial $q_{1}$ profile is diagnosed from saturation adjustment; $N_{\mathrm{a}}$ is the sum of interstitial aerosol $N_{\mathrm{ad}}$, cloud droplets $N_{\mathrm{d}}$, and rain $N_{\mathrm{r}}$.

In Fig. 3, red and blue curves show $y$-averaged profiles of $u$ and $v$, liquid water mass mixing ratio $q_{1}, q_{\mathrm{t}}$, absolute temperature $T_{\mathrm{abs}}$ and cloud droplet concentration $N_{\mathrm{d}}$ for up- 


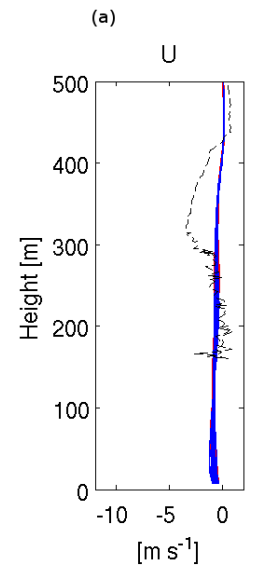

(b)

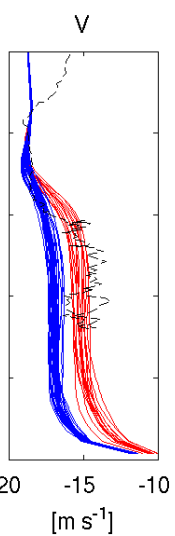

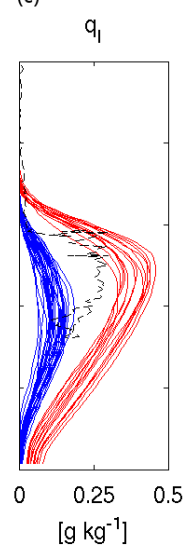

(d)

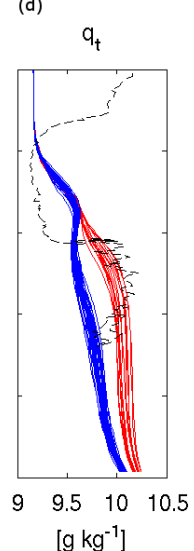

(e)

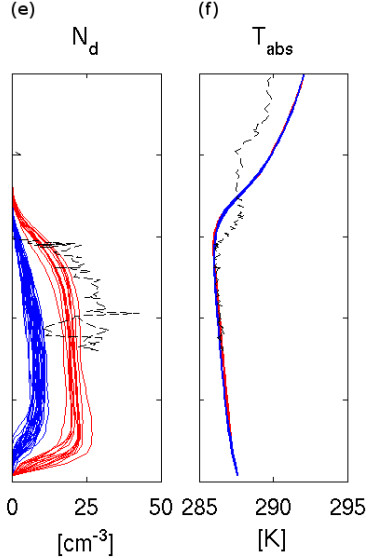

Figure 3. Profiles of $y$-averaged $u$ and $v$ winds, liquid water mass mixing ratio $q_{1}$, total water mass mixing ratio $q_{\mathrm{t}}$, absolute temperature $T_{\text {abs }}$, and cloud droplet concentration $N_{\mathrm{d}}$ after $8 \mathrm{~h}$, immediately before the ship track perturbation is introduced. Profiles are sampled at the locations of mesoscale updrafts (red curves) and downdrafts (blue curves), identified by maxima or minima in the $y$-averaged liquid water path.

drafts and downdrafts from the control run at hour 8, overplotted with the aircraft observations (black curves). The coherent roll organization of the boundary layer results in considerable differences in wind shear, $q_{1}$, and $N_{\mathrm{d}}$ between the roll-scale updrafts and downdrafts. For instance, wind speeds are $2-3 \mathrm{~m} \mathrm{~s}^{-1}$ faster in the downdrafts, since surface drag decelerates the flow before it ascends in the updrafts. Total water content in the updrafts is substantially larger than the downdrafts, reflecting the strong precipitation within the updrafts and broader downdraft regions. The initial stair-step temperature structure above the inversion has been mixed/diffused out after $8 \mathrm{~h}$. If the observed structure results from the boundary layer collapse process discussed in Ackerman et al. (1993), this suggests that the model is too diffusive in the region above the inversion or perhaps allows mixing not present in the real case. Alternatively, the observed structure may result from layered advection.

Since the observed wind shear at cloud top is large and $N_{\mathrm{d}}$ is at the upper end of the observational range, it is likely that the aircraft profiled through the center of a roll-scale updraft. The forcing parameters and initial conditions have therefore been tuned to match the mean updraft structure after the $8 \mathrm{~h}$, when the roll vortices are fully developed and the ship track is inserted.

Because of the low cloud base, the C-130 could not radiometrically observe the SST. Taylor and Ackerman (1999) used a sea surface temperature (SST) of $287 \mathrm{~K}$; in our pilot simulations, the $T_{\mathrm{abs}}$ and $q_{1}$ profiles matched observations better with an SST of $288 \mathrm{~K}$, so that is used here. With our choice of geostrophic wind profile and SST, the final updraft profile matches the observations reasonably well, though the inversion jumps are smeared somewhat by averaging due to variations in cloud top along the $y$ axis.

\subsection{Radiation}

Since the observations are inadequate to resolve temporal evolution of the other meteorological forcings in this case, radiative forcing is diurnally averaged. The model uses an insolation-weighted solar zenith angle appropriate to the date and latitude (13 June, $\left.34^{\circ} \mathrm{N}\right)$.

\subsection{Subsidence}

A constant divergence assumption is applied from $3000 \mathrm{~m}$ to the surface, implying a linear subsidence profile which acts as a large-scale forcing on the thermodynamic and microphysical fields. Accurate divergence measurements are quite difficult to obtain from observations; ERA-interim reanalysis (Dee et al., 2011) values for subsidence are quite variable in space and time along the coast of Southern California for the Sanko Peace case. We used an empirically determined divergence of $6.4 \times 10^{-6} \mathrm{~s}^{-1}$, which maintains a realistic and fairly constant MBL height through the majority of the simulation.

\subsection{Microphysics}

The initial MBL aerosol concentration is set to 10 per $\mathrm{mg}$ dry air for the baseline case. Aerosol concentrations given in these units are conserved for adiabatic parcel motions, and thus preferred. This is comparable to the mean $N_{\mathrm{d}}$ reported by Taylor and Ackerman (1999) (their values are reported in units of $\mathrm{cm}^{-3}$, which are roughly $30 \%$ larger than values in units of $\mathrm{mg}^{-1}$ within the shallow boundary layer; this comparison also assumes that in the model, most aerosol will be activated in updrafts, which holds for the simulated conditions). The initial geometric mean radius of the aerosol is chosen as $0.1 \mu \mathrm{m}$. Free tropospheric aerosol is set to zero, as 
aircraft observations showed negligible $\mathrm{CN} / \mathrm{CCN}$ above the inversion. Thus the only supply of aerosol to the cloud layer is from the parameterized surface salt flux, which is large due to the high wind.

After $8 \mathrm{~h}$ of simulation, we branch off a ship track run. To represent the track, the aerosol concentration between $z=0-100 \mathrm{~m}$ in a single line of grid columns down the center of the domain along the $y$ axis is instantaneously set to $s=15000 \mathrm{mg}^{-1}$, with a geometric mean radius of $0.1 \mu \mathrm{m}$. This approach is an approximation to the emissions from a ship steaming into the low-level wind. It would be more realistic to insert the aerosol at a location that follows the ship motion, but given the ship relative wind speed $V_{\text {rel }}=20 \mathrm{~m} \mathrm{~s}^{-1}$, the track would take only $10 \mathrm{~min}$ to advect across the $12.8 \mathrm{~km}$ length of the domain in the $y$ direction. Our initialization procedure makes the track evolve similarly at all $y$, allowing us to conveniently use $y$ averaging to robustly characterize the overall track evolution. The track simulation is continued for another $8 \mathrm{~h}$. For comparison, we also continue the control run with no added ship emissions.

We justify our choice of $s$ as follows. First, we link the grid perturbation $s$ and the implied aerosol source strength $S$. Given the perturbed depth $h=100 \mathrm{~m}$, horizontal grid spacing $\Delta x$ of $50 \mathrm{~m}$, air density $\rho_{\mathrm{a}}$ of $1.2 \mathrm{~kg} \mathrm{~m}^{-3}$, and fraction of viable $\mathrm{CCN} f_{\mathrm{CCN}}$ set to 0.15 ,

$$
\begin{aligned}
s & =f_{\mathrm{CCN}} S /\left(\rho_{\mathrm{a}} h \Delta x V_{\mathrm{rel}}\right) \\
& =15000 \mathrm{mg}^{-1} \rightarrow S=1.2 \times 10^{16} \mathrm{~s}^{-1} .
\end{aligned}
$$

Taylor and Ackerman (1999) performed their 1-D simulation of the Sanko Peace with an implied $S$ of $3.0 \times 10^{16} \mathrm{~s}^{-1}$. They based their choice on the aerosol measurements of the Cosco Tai He, described in Hobbs et al. (2000). Their implied source was twice the strength of the upper bound derived in Hobbs et al. (2000), done in order to counteract the underprediction of supersaturation (and thus activation) in their model. Since the aerosol scheme used in our study only includes the accumulation mode, we further need to assume a value of $f_{\mathrm{CCN}}$. Ferek et al. (1998) found that $10-30 \%$ of particles emitted are initially activated, while increasing supersaturation over time could contribute to increased activation downstream, along with the possibility of further $\mathrm{CCN}$ production via gas deposition growth of Aitken mode particles to $\mathrm{CCN}$ active size. Aircraft measurements reported by Hobbs et al. (2000) estimated the initially activated fraction in a range from $4-25 \%$ with significant variation between the different ships sampled, with an estimate of $8 \%$ for the Cosco Tai He.

While the activation scheme in our model (Abdul-Razzak and Ghan, 2000) has some capability to capture changes in activation due to variations in updraft strength, the growth of smaller particles to $\mathrm{CCN}$ active sizes is neglected. Assuming a larger value for $f_{\mathrm{CCN}}$ of 0.15 to roughly approximate the growth of $\mathrm{CN}$ to CCN downstream, our value of $S$ is $1.2 \times 10^{16} \mathrm{~s}^{-1}$, in line with the Hobbs et al. (2000) measure- ments for the Cosco Tai He. The Sanko Peace is a smaller ship, so the analog is not perfect, but the above calculations suggest our source strength is reasonable. We also perform a high-aerosol sensitivity study with an initial background boundary-layer aerosol concentration of $300 \mathrm{mg}^{-1}$. In an initial pilot simulation with the same source strength as in the control simulation, the plume rapidly diluted with minimal microphysical or macrophysical impact. In order to observe a clear signal, we increase the amplitude of the source by a factor of 10 for the high-aerosol case.

\section{Simulations}

Four simulations will be discussed. Run BaseSpinup is the starting point for our study, in which an initial sounding adapted from the ambient $\mathrm{C}-130$ vertical profile preceding sampling of the Sanko Peace track is spun up for $8 \mathrm{~h}$, at which time the model evolution agrees reasonably well in a quantitative sense with observations of the key thermodynamic and microphysical variables. At this point, the simulation is branched into runs BaseTrack, in which an aerosol perturbation representing the ship track is inserted, and BaseCtrl, which is left unperturbed; both branches are evolved for a further $8 \mathrm{~h}$. Two sensitivity studies are also performed. In run SensPerp, wind forcing is rotated $90^{\circ}$ clockwise to orient the rolls parallel with the longer $x$ dimension of the domain; the aerosol perturbation is now perpendicular to the roll structure, resulting in more rapid turbulent diffusion through the boundary layer. Lastly, run SensHiAer enhances the background aerosol concentration and that of the ship track perturbation as described in Sect. 4.4 above. Both sensitivity runs spin up for $8 \mathrm{~h}$, at which point the tracks are inserted and evolved for an additional $6 \mathrm{~h}$. Thermodynamic, dynamical, and microphysical statistics of the BaseCtrl run are nearly identical to those sampled from the background regions of the BaseTrack and SensPerp runs, suggesting that BaseCtrl is an adequate control for run SensPerp. A comparison between the general statistics of BaseCtrl and the out-of-track background environment in BaseTrack suggests that sampling of the background for SensHiAer provides an adequate control for that case, so separate control branches for the sensitivity runs are not performed.

\subsection{Background environment}

We begin by examining the evolution of the unperturbed background environment in BaseSpinup. Roll structures develop almost immediately, with a cross-axis length scale of a few hundred meters, growing to approximately $1.7 \mathrm{~km}$ at hour 4 and $2.5 \mathrm{~km}$ at hour 8 . Figure 4 shows $x-y$ plots of albedo, MBL depth averaged aerosol number, LWP, and surface precipitation intensity. The albedo plot strongly resembles the GOES imagery in the enlarged panel of Fig. 1 and other similar roll-organized boundary layers. The modeled 


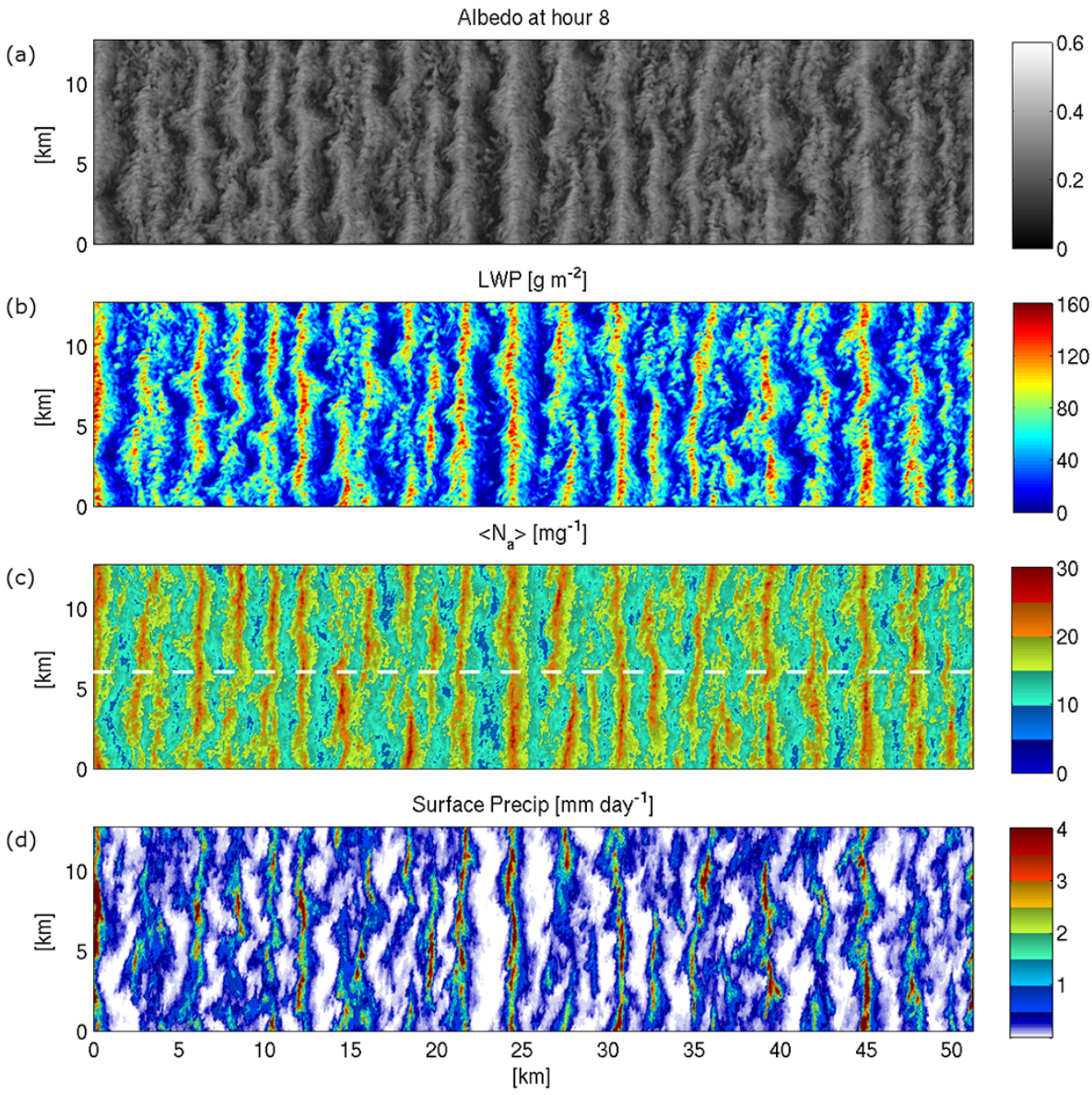

Figure 4. $x-y$ snapshots of domain (a) albedo $A$, (b) liquid water path (LWP), (c) total aerosol number concentration $\left\langle N_{\mathrm{a}}\right\rangle$, where brackets denote an average through the boundary layer depth, and (d) surface precipitation rate $\left(0.05 \mathrm{~mm} \mathrm{day}^{-1}\right.$ threshold $)$ for run BaseTrack at hour 8 .

roll wavelength is smaller than the approximately $5 \mathrm{~km}$ scale in the satellite imagery, which we attribute to the continued upscale evolution of the real boundary layer vs. an $8 \mathrm{~h}$ spinup from rest in the model.

LWP and albedo maxima (minima) mark the updrafts (downdrafts). Despite the very shallow boundary layer, LWP averages $\sim 100 \mathrm{~g} \mathrm{~m}^{-2}$ in the updrafts, with maxima exceeding $150 \mathrm{~g} \mathrm{~m}^{-2}$. Cloud base beneath the updrafts is mostly at the surface. While there are large variations in albedo in the cross-roll direction, domain cloud cover is quite high ( $\sim 87.5 \%$ at hour 8 , based on a $10 \mathrm{~g} \mathrm{~m}^{-2}$ minimum cloud water path (CWP) threshold). Aerosol number concentrations are $25-30 \mathrm{mg}^{-1}$ in the updrafts, where air recently in contact with the surface source is converged, while downdraft air is aerosol-depleted $\left(\sim 10 \mathrm{mg}^{-1}\right)$ due to collisioncoalescence losses in the clouds and mixing with the pristine air entrained from above. Domain average surface precipitation is $0.5 \mathrm{~mm} \mathrm{day}^{-1}$, but locally, precipitation is up to $6 \mathrm{~mm} \mathrm{day}^{-1}$ in narrow regions beneath the updrafts with highest LWP, and such rain bands contribute a significant fraction of the mean precipitation.
Figure 5 shows an $x-z$ snapshot at hour 8 of the $y$ averaged vertical velocity and a slice of total aerosol number concentration $N_{\mathrm{a}}$ taken across the domain at $y=6.4 \mathrm{~km}$. For reference, the cloud contour $q_{\mathrm{c}}=0.01 \mathrm{~g} \mathrm{~kg}^{-1}$ is also shown. In the simulation, a small amount of aerosol detrains in the layer immediately above the rolls as a result of evaporation and mixing. The observations had essentially no aerosol above cloud top (with one exception discussed below in Sect. 5.3), suggesting the model may again be slightly too diffusive with the very sharp vertical gradient in the aerosol field. Typical peak vertical velocities in the updrafts are 0.5 $0.8 \mathrm{~m} \mathrm{~s}^{-1}$ in very narrow bands of $\sim 200 \mathrm{~m}$ wide (variations in the updraft position along the roll diminish this when averaging in $y$ ). The $w$ slice also shows that the downdrafts are considerably broader than the updrafts.

\subsection{Ship track injection and evolution}

In this section, we analyze branch BaseTrack and compare it to the unperturbed BaseCtrl. The albedo $A$ is computed in each column from the TOA downwelling and upwelling 


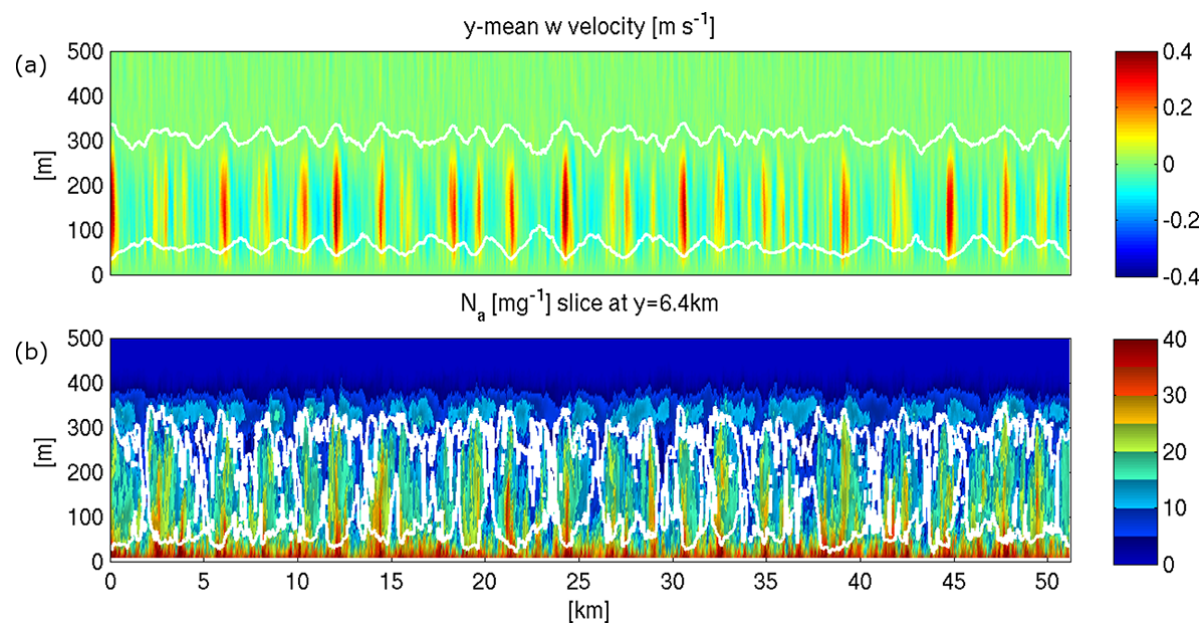

Figure 5. $x-z$ snapshots of (a) $y$-averaged vertical velocity $w$ and (b) vertical slice of total aerosol number concentration $N_{\mathrm{a}}$ at $y=6.4 \mathrm{~km}$ for run BaseTrack at hour 8 . White contours mark the $0.01 \mathrm{~g} \mathrm{~kg}^{-1}$ cloud water mixing ratio boundary. Differences in contour appearance result from $y$-average applied to the fields in (a).

shortwave radiative fluxes,

$A=\mathrm{SW}_{\uparrow}^{\mathrm{TOA}} / \mathrm{SW}_{\downarrow}^{\mathrm{TOA}}$.

Figure 6 shows the albedo $A$ at $0.5,1.5,3.0$, and $8.0 \mathrm{~h}$ after the aerosol injection, which is initially below a roll-scale updraft, producing a sharp, bright albedo signature which diffuses with time. For most of the following discussion, we consider Hovmöller plots of the salient fields, interpreting downstream distance as the time after injection multiplied by the $20 \mathrm{~m} \mathrm{~s}^{-1}$ ship-relative wind speed. Plots of albedo and surface precipitation use data output once a minute from the model, and are formed by combining transects at $y=6.4 \mathrm{~km}$ from all times. Calculation of the $\left\langle N_{\mathrm{a}}\right\rangle$ and LWP fields required data available in the 3-D outputs once every $10 \mathrm{~min}$. In order to better represent the variability of these fields, we substitute spatial resolution for time resolution of these variables by sequentially cycling through transects at each of the $10 y$ locations nearest $y=6.4 \mathrm{~km}$ for each 3-D output, yielding the same number of transects for all fields. Note that these plots present a highly compressed view of the along-track direction, in that the 8 simulated hours correspond to a downstream distance of $576 \mathrm{~km}$, given the $20 \mathrm{~m} \mathrm{~s}^{-1}$ ship-relative surface wind speed, while the cross-track domain width is $48 \mathrm{~km}$. The right-hand axis of panel d in Fig. 7 and Fig. 16 shows equivalent downstream distance.

The albedo of unbroken stratocumulus clouds can be related to their cloud droplet concentration (which is in turn related to $\left.\left\langle N_{\mathrm{a}}\right\rangle\right)$ and LWP; the relative importance of $N_{\mathrm{d}}$ and LWP contributions to the track albedo response is explored in Sect. 5.6. Figure 7 shows a Hovmöller plot of the time evolution of albedo, $\left\langle N_{\mathrm{a}}\right\rangle, \mathrm{LWP}$, and surface precipitation.

At 30 min after injection, the ship track aerosol has been laterally mixed across slightly more than $1 \mathrm{~km}$, diluting the initial concentration from an MBL depth-averaged value of $5000 \mathrm{mg}^{-1}$ to values between $100-325 \mathrm{mg}^{-1}$. Assuming nearly complete activation (as is simulated in this case) and a vertically well-mixed profile, this gives a peak $N_{\mathrm{d}}$ of $420 \mathrm{~cm}^{-3}$ at $300 \mathrm{~m}$ altitude, a value nearly 4 times larger than observed in an observational transect sampled $30 \mathrm{~min}$ downstream of the ship (Taylor and Ackerman, 1999). Imperfect alignment of the ship's course and the roll axis may have led in reality to more rapid turbulent diffusion of the aerosol than in the simulation. Consistent with this hypothesis, the observed track width of $4 \mathrm{~km}$ is 4 times as large as the simulated width. Section 5.3 further discusses of how track orientation affects track width. Other possibilities are that the effective aerosol injection strength $S$ may be overestimated, or that the plume takes more than $30 \mathrm{~min}$ to develop a quasisteady aerosol size distribution with a fully developed accumulation mode.

In contrast with the obvious aerosol perturbation and albedo increase, there is a negligible change in LWP between the track and the surrounding environment after $30 \mathrm{~min}$ (Fig. 7c). The lack of a strong cloud macrophysical response indicates that the radiative response of the cloud at this time results entirely from the Twomey effect. Despite the shift towards smaller cloud droplets, substantial surface precipitation remains inside the simulated track at this time. Figure $7 \mathrm{~d}$ shows no real difference in precipitation rate between the track and background. The time lag between the aerosol injection and the visible manifestation of the track in the pseudo-albedo field gives a sense of the timescale for the perturbation of the microphysics via activation. There is an additional delay before changes in cloud properties alter surface precipitation characteristics, as existing rainwater in the column takes some time to sediment out. The narrow band of peak rain rates exceeding $4 \mathrm{~mm}_{\text {day }}{ }^{-1}$ disappears $20 \mathrm{~min}$ 

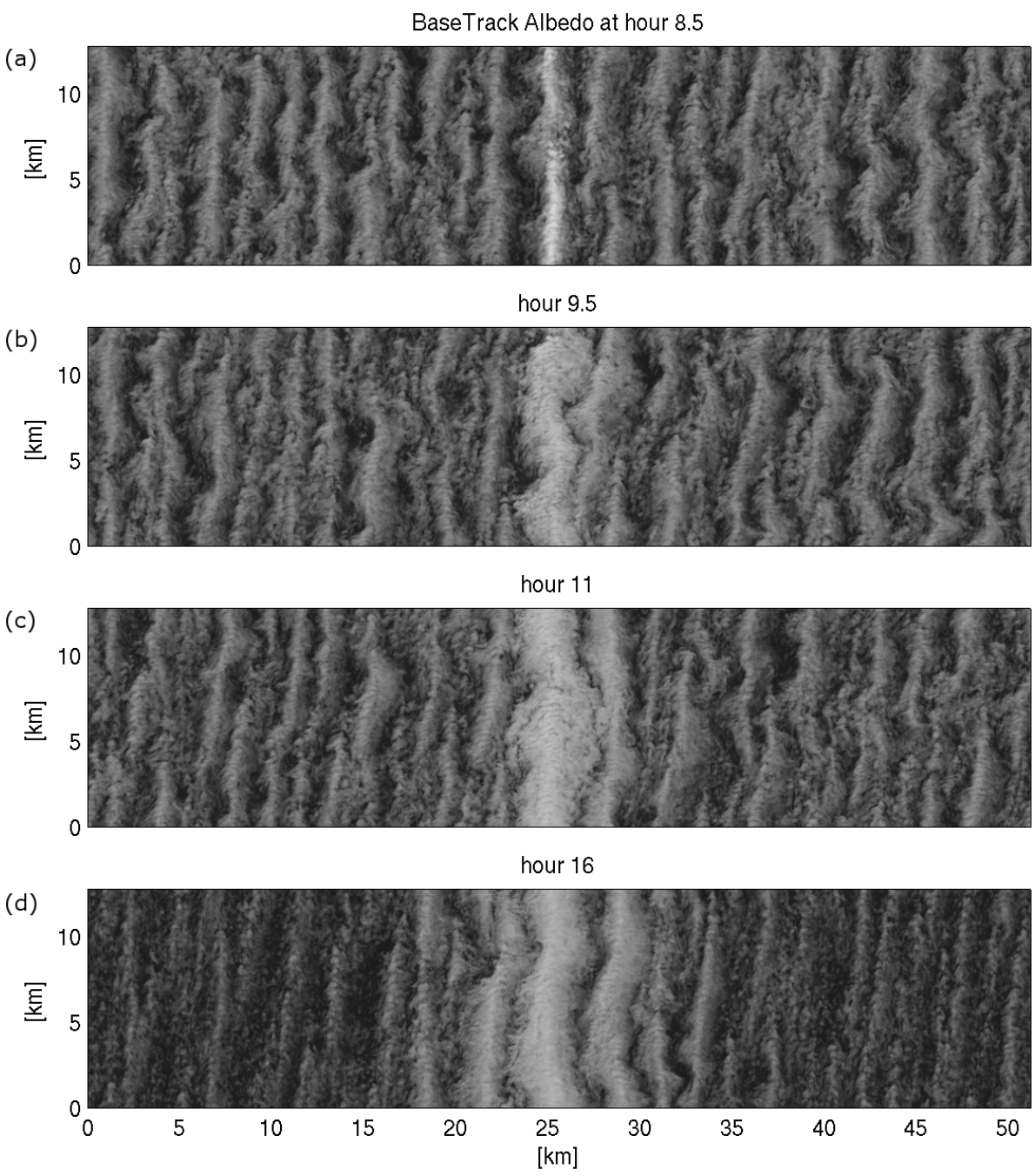

Figure 6. $x-y$ snapshots of albedo for run BaseTrack at hours (a) 8.5 (half an hour after track injection), (b) 9.5, (c) 11, and (d) 16 .

after visible cloud brightening (50 min after injection), and virtually all surface precipitation ceases by hour 9.5 .

The aerosol perturbation diffuses slowly over the next hour, broadening the track from 1 to $3 \mathrm{~km}$ by laterally mixing into two additional roll updrafts and diluting MBL depthaveraged aerosol number concentrations within the track to $60-100 \mathrm{mg}^{-1}$. Peak updraft LWP values diminish within the track 90 min after injection but increase in the regions adjacent to the central updraft. This lateral redistribution of cloud water out of the updrafts is likely due to drizzle inhibition. Figure $7 \mathrm{~d}$ shows essentially no area beneath the central updraft of the track where surface precipitation exceeds $0.25 \mathrm{~mm} \mathrm{day}^{-1}$ after $90 \mathrm{~min}$, as compared to peak rates of $\sim 4-6 \mathrm{~mm}$ day $^{-1}$ under the background updraft cores.

After $3 \mathrm{~h}$, the track has spread to $5 \mathrm{~km}$ width, and MBL depth-averaged $N_{\mathrm{a}}$ has diluted to $30-60 \mathrm{mg}^{-1}$. The rough inverse scaling of $N_{\mathrm{a}}$ with lateral dispersion (boundary layer depth is not changing much within this period) suggests that local source and sink terms are of secondary importance compared to the advective redistribution of the original aerosol perturbation within the track; we will examine the aerosol budget of the track more precisely below. LWP and optically thick cloud increase throughout the track, with peak LWPs exceeding $100 \mathrm{~g} \mathrm{~m}^{-2}$. While surface precipitation begins to recover under the track 150 min after injection, the average rain rate in the track remains suppressed, as the maximum rain rate in the track is less than half that of the background despite increasing LWP.

At the end of the simulation, $8 \mathrm{~h}$ after the aerosol injection, the track is $\sim 15 \mathrm{~km}$ wide, spanning six distinct updrafts, with LWPs as high as $100-140 \mathrm{~g} \mathrm{~m}^{-2}$. These large values of LWP coupled with slow declines in $N_{\mathrm{a}}$ (and hence $N_{\mathrm{d}}$ ) result in the redevelopment of drizzle and surface precipitation beneath the updrafts in the track.

In contrast with prior LES modeling work of idealized ship tracks in a deeper, open-cell boundary layer (Wang and 

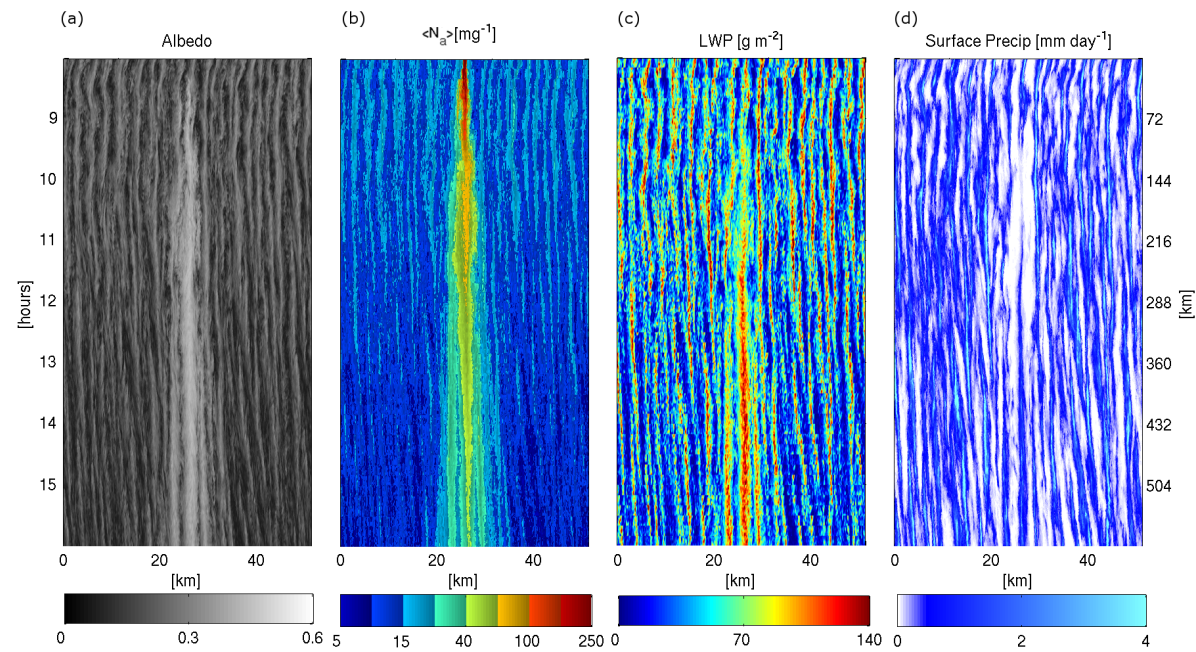

Figure 7. $x-t$ Hovmöller plots for run BaseTrack of (a) $A$, (b) $\left\langle N_{\mathrm{a}}\right\rangle$, where brackets denote a column average through the depth of the MBL, (c) LWP, and (d) surface precipitation rate. The axis on the right-hand side of the albedo plot shows the equivalent downstream distance from the ship.
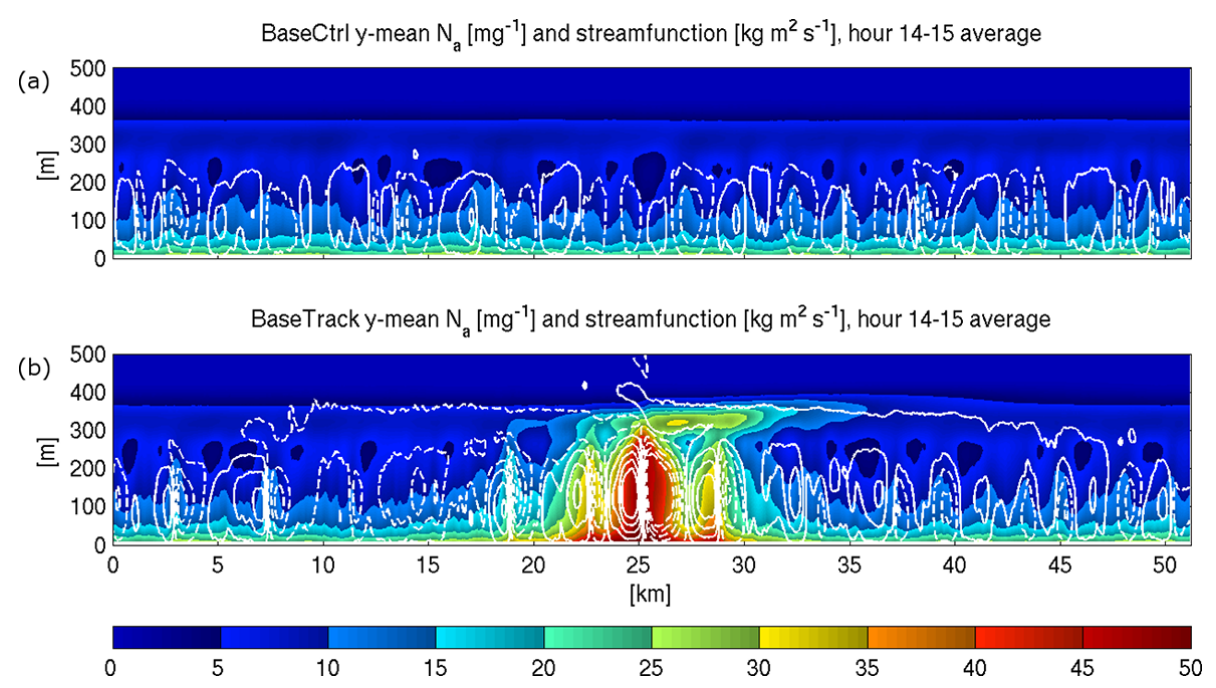

Figure 8. $x-z$ slice of $y$-averaged aerosol concentration $N_{\mathrm{a}}$ and $y$-averaged stream function $\psi$ for runs (a) BaseCtrl and (b) BaseTrack in a mean over hour 14 to 15 , the seventh hour after track injection. Positive stream function (solid white contours) indicates a counterclockwise circulation, while negative stream function (dashed contours) indicates a clockwise circulation. Contours shown have magnitudes of \pm 5 , 20, $35,50,65 \mathrm{~kg} \mathrm{~m}^{2} \mathrm{~s}^{-1}$.

Feingold, 2009; Wang et al., 2011), Fig. 7a does not show a suppression of background cloud albedo on the flanks of the track due to an induced secondary circulation. Thus, in this shallow, collapsed boundary layer, the simulated track induces a more significant area-integrated albedo perturbation than those seen in previous studies.

Figure 8 compares the $y$-averaged stream function and aerosol fields averaged over hour 15 (the seventh hour after the BaseTrack aerosol injection) in simulations BaseTrack and BaseCtrl. Over hour 15, aerosol-cloud-precipitation feedbacks within the track act to reinforce the roll circulation, while the rolls outside the track (and throughout Ba-
seCtrl) become shallower and weaker as the boundary layer collapses. While this would also tend to strengthen the downdrafts and induce cloud thinning on the edges of the track, this does not seem to reduce albedo there. A possible explanation is that the shift in droplet sizes that has inhibited drizzle and reduced moisture desiccation in the updrafts overcomes any tendency for cloud thinning in downdrafts.

\subsubsection{Continued evolution of the background state}

During the $8 \mathrm{~h}$ after aerosol injection, the background environment also evolves significantly, with declines in mean 

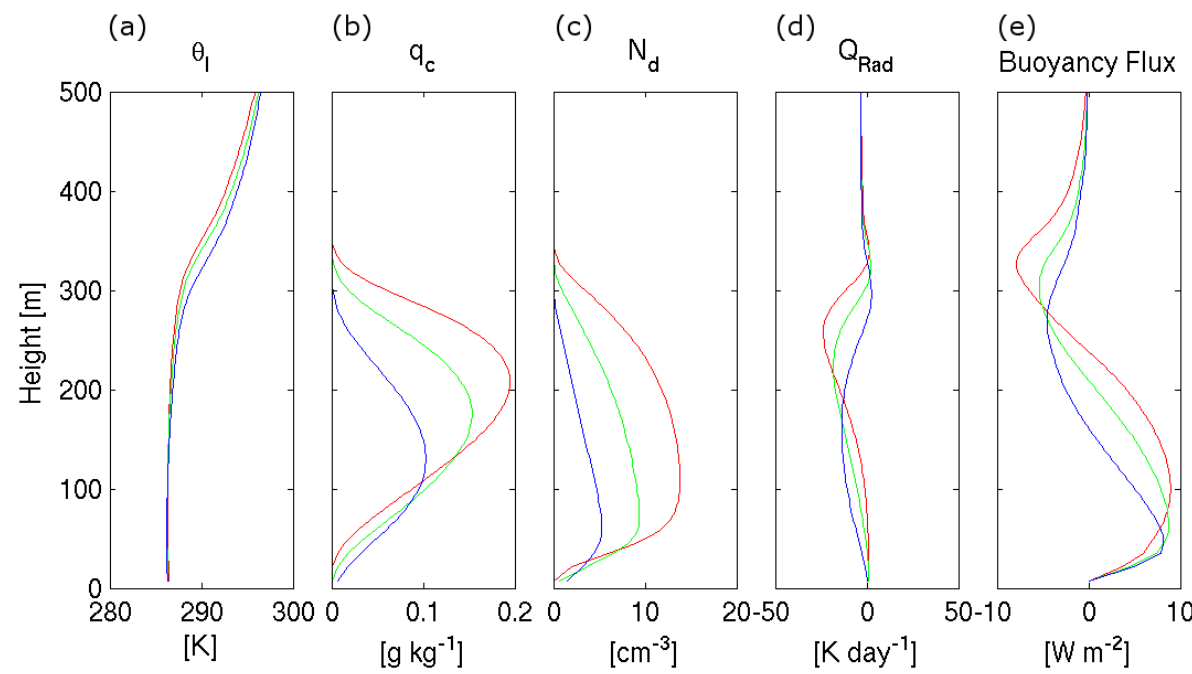

Figure 9. Domain average profiles from run BaseCtrl for (a) liquid-water potential temperature $\theta_{\mathrm{l}}$, (b) cloud water $q_{\mathrm{c}}$, (c) cloud droplet number concentration $N_{\mathrm{d}},(\mathbf{d})$ radiative heating rate $Q_{\mathrm{RAD}}$, and (e) resolved buoyancy flux $B$. Times shown are for hours 8 (red), 12 (green), and 16 (blue).

LWP (38\%), $N_{\mathrm{a}}(34 \%)$ and albedo $(30 \%)$, relative to their hour- 8 peak. The decline in LWP is due to a loss of cloud water, as the rain water path (RWP) for the background remains approximately $10 \mathrm{~g} \mathrm{~m}^{-2}$ throughout.

To better understand this evolution, we analyze domainmean statistics for hours 8-16 of the unperturbed control branch, for which there is no track that needs to be removed. Figure 9 shows profiles of liquid-water potential temperature $\theta_{1}$, cloud water $q_{\mathrm{c}}, N_{\mathrm{d}}$, radiative heating rate $Q_{\mathrm{RAD}}$, and resolved buoyancy flux $B$ at hours 8,12 , and 16 . As mean $N_{\mathrm{d}}$ rapidly diminishes, the cloud becomes optically thinner. This causes the radiative cooling peak, which initially resides just below cloud top, to broaden and shift deeper into the cloud layer, acting to stabilize the upper MBL, as seen in the progressively shallower region of positive buoyancy flux and less well-mixed $\theta_{1}$ profiles at hours 12 and 16 . The combination of weakening updrafts and larger cloud droplet sizes resulting from decreased $N_{\mathrm{d}}$ makes it increasingly difficult to support cloud, which leads to a collapse of the boundary layer, as earlier found in a one-dimensional closure model by Ackerman et al. (1993). Much of the MBL turbulent kinetic energy is shear-driven, but this does not prevent the collapse. The increasingly negative buoyancy flux in the updrafts causes the roll structure to become less coherent and wavelengths to shrink, in agreement with the results of sensitivity studies in Chlond (1992) and Müller and Chlond (1996). For further detail regarding boundary layer roll dynamics and the relative importance of shear and buoyancy, the interested reader is referred to the LES study of Glendening (1996).

\subsubsection{Aerosol number budget inside and outside the track}

In order to further understand the evolution of the track, we examine the MBL depth-averaged aerosol number budget. The only source is the wind speed dependent surface flux, while autoconversion, accretion, interstitial scavenging, and entrainment dilution (since there is no aerosol above the boundary layer) all act as sinks. All these terms are a function of the local column properties, while advection redistributes aerosol between columns.

In Fig. 10, we examine time series of the area averaged $\left\langle N_{\mathrm{a}}\right\rangle$ budget and source terms inside the background environment (left panel) and ship track (right panel). Grid columns are classified as part of the track if their $\left\langle N_{\mathrm{a}}\right\rangle$ exceeds twice the domain median $\left\langle N_{\mathrm{a}}\right\rangle$ of the unperturbed control branch at the same point in time. The local entrainment rate $w_{\mathrm{e}}$ is calculated using a flux-jump approach (see e.g., Faloona et al., $2005)$ on $8 \times 8$ tiles of grid columns. The entrainment tendency is then calculated as $\left.\left\langle N_{\mathrm{a}}\right\rangle\right|_{w_{\mathrm{e}}}=w_{\mathrm{e}}\left(N_{\mathrm{a} F \mathrm{FT}}-\left\langle N_{\mathrm{a}}\right\rangle\right) / z_{\mathrm{i}}$, where $w_{\mathrm{e}}$ is the entrainment rate, $N_{\mathrm{a}}$ FT is the free tropospheric aerosol concentration (zero in this case), and $z_{\mathrm{i}}$ is the inversion height, using coarsened spatial maps of $z_{\mathrm{i}}$ and $\left\langle N_{\mathrm{a}}\right\rangle$.

Accretion is initially the largest component of the loss term in both the background environment and track, with a large contribution from scavenging of interstitial aerosol. For the track, the large initial spike in accretion is due to the activation of many new cloud droplets at the base of updrafts with significant precipitation, initially allowing for large loss of aerosol number. However, the simultaneous increase in $N_{\mathrm{d}}$ drives the cloud droplet distribution towards a smaller mean radius, reduces autoconversion efficiency, and inhibits new 

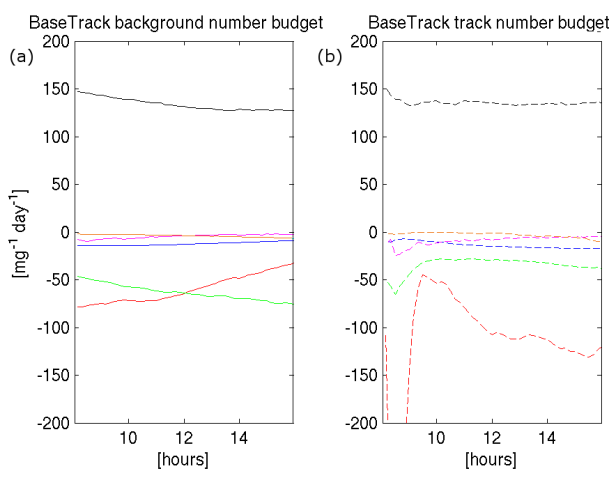

Figure 10. Regional aerosol budgets for run BaseTrack. (a) Time series of budget term magnitude in the background (solid) and (b) within the ship track (dashed).

drizzle formation. After this brief period of reduced accretion, increased LWP resulting from earlier drizzle suppression begins to enhance precipitation again, with efficient collection of $N_{\mathrm{d}}$ in large-scale updrafts. In the background, both accretion and autoconversion diminish, as the continual reduction in background $N_{\mathrm{d}}$ leaves a smaller available population of droplets to be scavenged by precipitation or to autoconvert into drizzle.

The second largest term is the interstitial scavenging of aerosol by cloud, which increases throughout the simulation in the background environment, but is sharply reduced within the track. This is somewhat counter-intuitive, as the collision efficiency for interstitial scavenging increases with decreasing droplet diameter (e.g., see the appendix of Berner et al., 2013, and references therein). While detailed examination of this effect is beyond the current scope, a possible interpretation is that while the collision efficiency may increase in the track, the reduced sedimentation rate of the smaller cloud droplets decreases the gravitational collection factor in the interstitial scavenging term, causing this term to be smaller in the track compared to the background.

Entrainment is the third largest number sink term within the track. Entrainment dilution rate is initially larger in the track due to an enhanced entrainment rate and the larger aerosol concentration in the boundary layer, since dilution is proportional to the difference between the boundary layer and FT concentrations. As the track broadens with lateral mixing and the aerosol concentration in the track approaches that of the background, dilution weakens and becomes the weakest sink term at the end of the simulation. Outside the track, entrainment (and therefore entrainment dilution) is much weaker, and autoconversion is the third strongest term.

The final sink is due to loss of aerosol number to the sea surface in sedimenting cloud droplets and secondarily in falling raindrops. This term is small but non-negligible and improves budget closure, since the simulated cloud frequently extends to the sea surface (Fig. 5). Within the track, it is small during the first $5 \mathrm{~h}$ due to the small (and hence slowly falling) cloud droplets. By the end of the simulation, though, the cloud droplets are more numerous in the track and have become large enough to sediment more efficiently, leading to a larger sedimentation loss than in the background at that time.

\subsection{Comparison with observations}

The MRF C-130 flew a series of in-cloud and above-cloud transects perpendicular to the track $40 \mathrm{~km}$ from the Sanko Peace. This distance was estimated by Taylor and Ackerman to be approximately $35 \mathrm{~min}$ downwind, assuming ship relative winds of $20 \mathrm{~m} \mathrm{~s}^{-1}$. Taylor and Ackerman (1999) provided detailed analysis of these aircraft observations.

We compare these observations with the simulated ship track. As discussed above, due to uncertainties in the actual aerosol source strength and alignment between the track and background roll structure, it is unrealistic to expect a perfect match in aerosol concentration or track width. For comparison, we examine transects from model output at $40 \mathrm{~min}$ after the aerosol perturbation is injected, as 3-D fields were saved every $10 \mathrm{~min}$. Note that for this comparison, $N_{\mathrm{d}}$ has units of $\mathrm{cm}^{-3}$.

Figure 11 compares $y$-averaged transects of droplet number concentration $N_{\mathrm{d}}$, effective radius $r_{\mathrm{e}}$, and albedo $A$ with comparable plots reproduced from Figs. 2, 4 and 5 of Taylor and Ackerman (1999). The $x$ axis of the original Taylor and Ackerman figures is given in time. Assuming constant heading and $100 \mathrm{~m} \mathrm{~s}^{-1}$ flight speed, each minute covers $6 \mathrm{~km}$, so their transects are $24-30 \mathrm{~km}$ in length. The in-cloud leg analyzed by Taylor and Ackerman was flown at $285 \mathrm{~m}$ altitude, so the model transects of $N_{\mathrm{d}}$ and $r_{\mathrm{e}}$ are taken from the closest model level $(283.75 \mathrm{~m})$. For the $N_{\mathrm{d}}$ transect, the qualitative agreement with the aircraft observation is quite good. Cloud cover at this level is lower than in the observations, resulting in a low bias to the background $N_{\mathrm{d}}$, but the peaks of $20 \mathrm{~cm}^{-3}$ are consistent with observations (the average is not cloud-conditional, as spatial variability and $N_{\mathrm{d}}$ gradients create noise). The track itself is narrower than in the observations at this time, spanning barely $2 \mathrm{~km}$ as opposed to $4 \mathrm{~km}$ in the transect presented by Taylor and Ackerman. The narrower track width in the model helps explain larger peak concentrations relative to the observations, with the maximum of $178 \mathrm{~cm}^{-3}$ significantly in excess of the observed peak of $130 \mathrm{~cm}^{-3}$. However, the average simulated value across a $2 \mathrm{~km}$ window including the track is only $67 \mathrm{~cm}^{-3}$, similar to the observed mean of $60 \mathrm{~cm}^{-3}$ across the $\sim 4 \mathrm{~km}$ wide track.

Taylor and Ackerman (1999) found that drizzle size droplets contributed significantly to the effective radius, as values of $r_{\mathrm{e}}$ determined from in situ distributions of cloud droplet sized particles were several $\mu \mathrm{m}$ smaller than those retrieved radiometrically, a discrepancy fixed by including drizzle-size droplets in the calculation. A modified effective radius is used within the model to include this effect: 
(a)

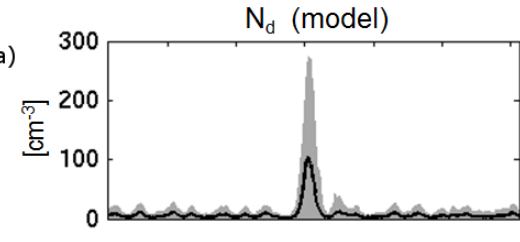

(b)

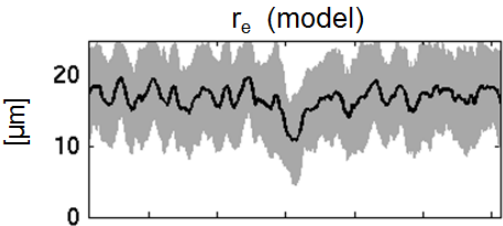

(c)

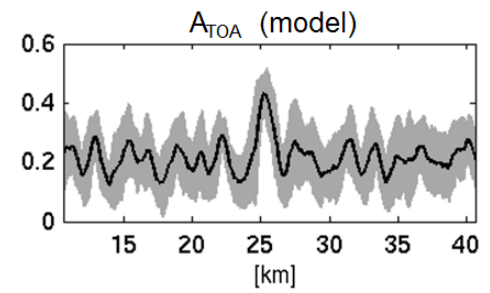

$\mathrm{N}_{\mathrm{d}}$ (obs)

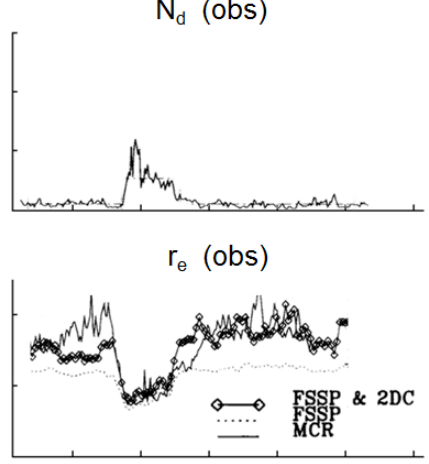

$A_{\text {Cld }}$ (obs)

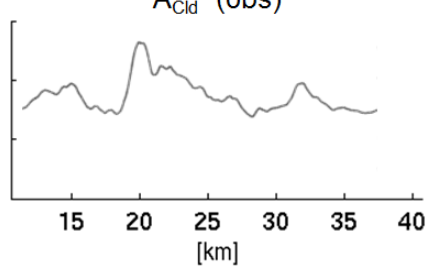

Figure 11. Model transects at hour 8.7 of (a) $N_{\mathrm{d}}$, (b) $r_{\mathrm{e}}$, and (c) albedo. We compare the modeled top of atmosphere albedo $\left(A_{\mathrm{TOA}}\right)$ with the observed cloud albedo $\left(A_{\mathrm{Cld}}\right.$, as the $3 \mathrm{~d}$ fields for radiative fluxes were not saved and thus computing a modeled cloud albedo is not possible. In each panel, the heavy black curve is the domain $y$-average, and the grey-filled region is bounded by $\pm 2 \sigma$ about the mean, where $\sigma$ is calculated at each $x$ as the square root of the variance of all values in $y$. Observations from Taylor and Ackerman (1999) Figs. 2, 4, and 5 are reproduced in the right hand column. The model transects are shown for the time that most nearly corresponds with the observed transects in terms of downstream evolution after aerosol perturbation (about $40 \mathrm{~min}$ ).

$r_{\mathrm{e}}=\frac{\left(q_{\mathrm{c}}+q_{\mathrm{r}}\right)}{\frac{q_{\mathrm{r}}}{r_{\mathrm{e}}}+\frac{q_{\mathrm{c}}}{r_{\mathrm{e}_{\mathrm{c}}}}}$.

The observations averaged two-second blocks of data for computing $r_{\mathrm{e}}$, which is equivalent to a four grid-point average in the model framework. In the second panel on the left, the model $r_{\mathrm{e}}$ transect shows a mean of $18 \mu \mathrm{m}$ within the background and a drop to $10 \mu \mathrm{m}$ within the track, in excellent agreement with the observations. The representative simulated $r_{\mathrm{e}}$ transect is noisier than the observations, likely in part due to the more broken cloud compared with the observed case, as well as the relatively coarse sampling of the spatial variability of the droplet distribution resulting from the $50 \mathrm{~m}$ horizontal grid spacing.

Aircraft albedo observations are not directly comparable with the model output, as they were measured just above cloud top, whereas the model values are for TOA and affected by the overlying atmosphere; thus here our comparison is mainly qualitative. The albedo transect clearly demonstrates the lower overall albedo and more broken nature of the modeled MBL structure. The observed albedo never falls below 0.27 , while in several spots the model albedo falls below 0.1 . The background peak albedos are broadly consistent at $\sim 0.3$ with the observations, suggesting that either evaporation of thin cloud flanking the large scale updrafts is excessive or precipitation is too intense within the model, removing liquid water that would otherwise be available for cloud flanking the updrafts. However, the albedo peak within the model transect of 0.47 yields a comparable increase relative to the background mean as does the observed value of 0.52 .

Figure 12 shows profiles of cloud and rain water conditionally sampled from the track and background at 40, 90 and 420 min after track injection, averaged over both updrafts and downdrafts. The rain mixing ratio is scaled by a factor of 4 for clarity. The background profile of $q_{1}$ (which includes both cloud and rain water), constructed by Taylor and Ackerman is overplotted in black. The peak in liquid water for the background is located near $210 \mathrm{~m}$, with cloud tops at or slightly above $300 \mathrm{~m}$. Significant rainwater remains in the column at $40 \mathrm{~min}$, but decreases are apparent near the top of the profile, as the autoconversion source of new drizzle is diminished with the shift to smaller cloud droplets. This profile is qualitatively consistent with the in situ measurements, which showed slight increases within the track of liquid water content (LWC) for the instruments most sensitive to cloud size droplets, and slight decreases of LWC for instruments with higher sensitivity to drizzle; this is qualitatively consistent with decreasing $q_{\mathrm{r}}$ and increasing CWP, depending on the cut-off diameters for the respective instruments. After 90 min, the peak in cloud water within the track has lifted to $250 \mathrm{~m}$ and liquid water content (LWC) has increased by $50 \%$ to $0.3 \mathrm{~g} \mathrm{~kg}^{-1}$, while rainwater in the track has become negligible. After $6 \mathrm{~h}$, the peak in track LWC has increased slightly while shifting back downwards to $225 \mathrm{~m}$. Drizzle 

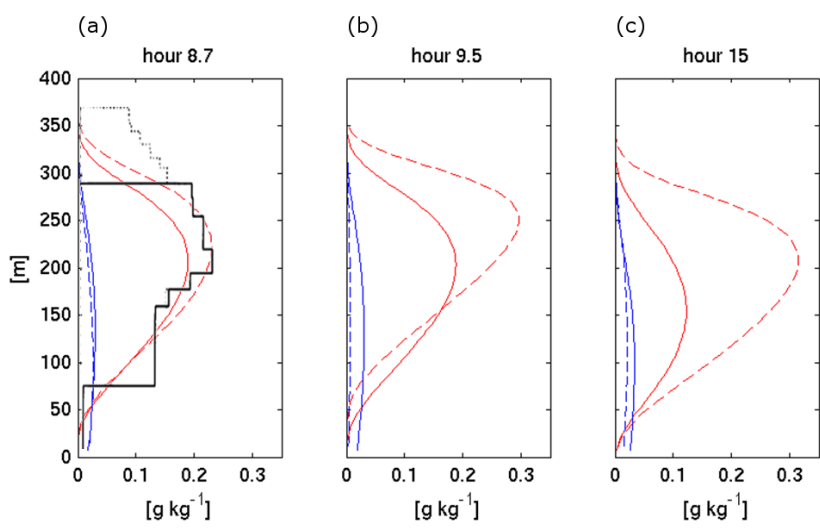

Figure 12. Profiles of cloud (red lines) and rain (multiplied by factor of 4 for clarity; blue lines) water mass mixing ratios, regionally averaged in the ship track (dashed lines) and background (solid lines) in run BaseTrack. Plots are shown for hours (a) 8.7, (b) 9.5, and (c) 15. Black overlay in (a) is the composited observational profile for $q_{1}$ from Taylor and Ackerman (1999).

in the track is recovering towards the background profile, though the background cloud water peak has decreased $20 \%$ while shifting downwards to $150 \mathrm{~m}$.

In Fig. 8, a plume of aerosol in the inversion layer is evidently emanating from the ship track, due to broadening of the inversion layer above the cloud top due to sheardriven mixing. One transect flown by the $\mathrm{C}-130 \mathrm{did}$ show an increase in Aitken mode particles above cloud top. The above-cloud aerosol plume was sufficiently surprising in an otherwise pristine environment to be explicitly noted in the flight summary. However, the observed concentrations $\left(\sim 15 \mathrm{~cm}^{-3}\right)$ were small compared both to those simulated and to the observed cloud droplet concentrations within the track. This is not definitive, as the available data are inadequate to tell how close to cloud top the data were taken, but it appears that more aerosol is detrained in the model than is supported by the observations.

While the simulated track maintains higher cloud tops than the background at $40 \mathrm{~min}$ after injection, it does not deepen as rapidly or as much as the observationally reported $100 \mathrm{~m}$ (Taylor and Ackerman, 1999). One hour after the aerosol perturbation, the difference between cloud tops inside vs. outside the track ranges between $20-30 \mathrm{~m}$. The maximum separation in run BaseTrack between cloud tops in the track and background is $60 \mathrm{~m}$, but this only develops by the end of the simulation and is driven more by the collapse of the background than the continual deepening of the ship track. Figure 13 shows a Hovmöller plot of the $y$-averaged entrainment derived using the local flux jump calculations; while averaging in $y$ blurs maxima in the surrounding environment, it is clear that the central circulation in the ship track is entraining air at least twice as rapidly as the background average. If aerosol concentrations were higher just above the entrainment zone than in the boundary layer, then this could act as

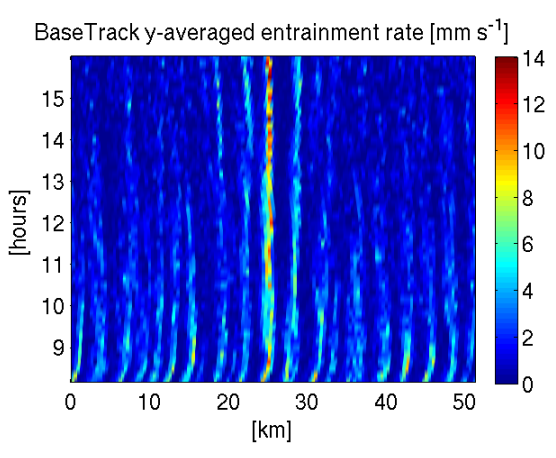

Figure 13. Hovmöller plot of $y$-averaged entrainment rate $w_{\mathrm{e}}$ for run BaseTrack.

a positive feedback that would accentuate the track. Given the highly elevated aerosol concentrations typical of a ship track, however, it is likely that entrainment is usually a negative feedback that enhances the dilution of track aerosol concentrations, since FT aerosol concentrations larger than the track values are likely rare in the remote MBL.

\subsection{Sensitivity of track to relative wind direction}

Etling and Brown (1993) noted that the presence of roll structures can have a profound influence on turbulent fluxes within the boundary layer, and that the effective turbulent diffusion can be highly anisotropic. This affects the dispersion of aerosol within shear driven boundary layers. The shear between updrafts and downdrafts of individual rolls tends to diffuse perturbations along them much more rapidly than mixing can transport a scalar between adjacent rolls. In the case of ship tracks, we expect ship tracks with a larger crossing angle relative to the roll axis to spread more rapidly than a track that parallels the roll axis. We tested this using run SensPerp by rotating the geostrophic wind $90^{\circ}$ clockwise, such that the ship track is now inserted perpendicular to the rolls rather than parallel to them. This run is spun up for the same initial $8 \mathrm{~h}$ period as in BaseSpinup, after which the track is inserted and the run continued for a further $6 \mathrm{~h}$. Figure 14 shows the albedo field for run SensPerp at hours 9, 11, and 13 ; rapid broadening of the track is readily apparent.

In Fig. 15, the background (blue), track (red), and domain averaged (black) statistics of albedo, $\left\langle N_{\mathrm{a}}\right\rangle, \mathrm{LWP}$, and precipitation are shown for SensPerp, BaseTrack, and SensHiAer (to be discussed below). The BaseTrack simulation is shown in the middle panel to facilitate comparison with both sensitivity studies. The fraction of the domain within the track at each time in each run can be inferred from the ratio of vertical distances of the black curve from the blue vs. from the red curve. The initial aerosol pulse is spread much more rapidly in SensPerp than in BaseTrack, indicated by the more rapid decrease of in track $\left\langle N_{\mathrm{a}}\right\rangle$ in Fig. 15, as the aerosol quickly enters all roll cells across the domain and rapidly disperses along the rolls. This suppresses precipitation across a broader 

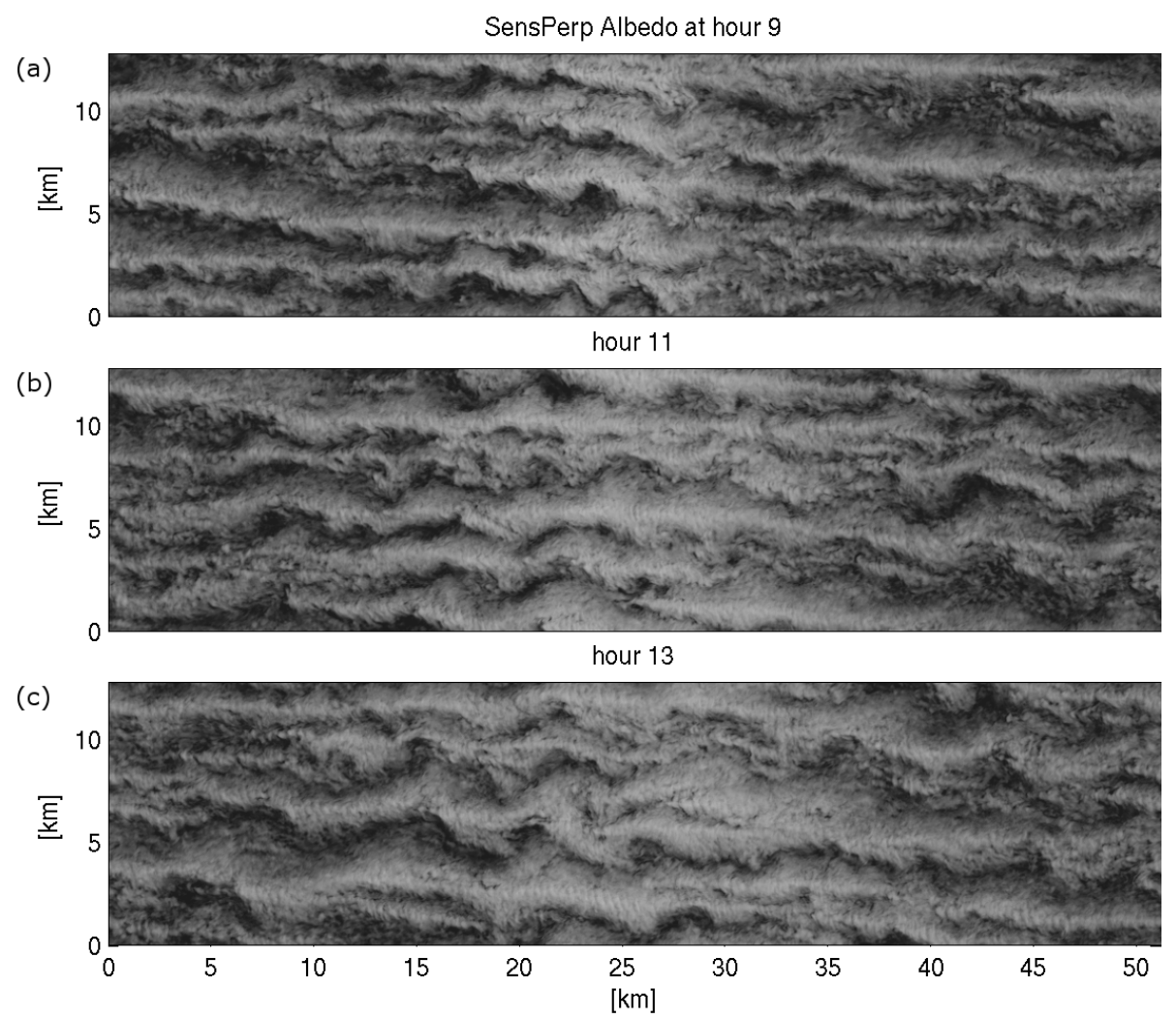

Figure 14. $x-y$ snapshots of albedo for run SensPerp at hours (a) 9 , (b) 11 , and (c) $13(1,3$, and 5 hours after the ship track perturbation is introduced).

area in SensPerp, increasing domain-mean LWP, $\left\langle N_{\mathrm{a}}\right\rangle$, and albedo. However, because the injected aerosol in SensPerp is distributed more broadly than in BaseTrack, the in-track perturbation is smaller, so precipitation more quickly recovers to environmental values.

The larger domain-mean albedo in SensPerp than in BaseTrack can be related to results of Wang et al. (2011). For their case, they found that for a precipitating boundary layer with a low background aerosol concentration, a larger domainmean albedo increase could be achieved with a uniform aerosol source across the whole domain (loosely analogous to SensPerp, regarding the enhanced lateral mixing as analogous to spreading the original source) than for a single point source (analogous to BaseTrack). In their non-precipitating cases, for a given domain-mean aerosol source, the domainmean albedo increase was independent of the injection configuration, indicating a more "linear" regime.

\subsection{Simulated track in a polluted environment}

In a second sensitivity study SensHiAer, the initial background aerosol concentration is set to $300 \mathrm{mg}^{-1}$. We also increase the injection aerosol source strength by a factor of 10 compared to the baseline case to make the track stand out clearly against the polluted background. The higher bound- ary layer aerosol concentration shifts the cloud droplet distribution to smaller sizes, limiting drizzle formation and reducing surface rain rates relative to the BaseTrack case. Reduced precipitation allows for a more turbulent cloud and greater entrainment, leading to boundary layer deepening, a thicker cloud, and larger LWP. During the $8 \mathrm{~h}$ spin-up before the aerosol injection, stronger entrainment dilution and cloud processing lead to a decline of $\left\langle N_{\mathrm{a}}\right\rangle$ to $100-120 \mathrm{mg}^{-1}$, while the boundary layer deepens to $\sim 400 \mathrm{~m}$.

The right column of Fig. 16 shows Hovmöller plots of albedo, $\left\langle N_{\mathrm{a}}\right\rangle, \mathrm{LWP}$, and surface precipitation, assembled similarly to Fig. 7. The Twomey effect renders the track visible in the first hour despite the bright surrounding cloud. Comparison of the right two columns of Fig. 15 shows that the track mean albedo gain is less than in clean cases, despite the much stronger aerosol injection, as the background cloud is significantly brighter.

Within the first hour, the LWP in the ship track decreases a few percent below the background, as is commonly observed in Type 2 ship tracks (Coakley and Walsh, 2002; Chen et al., 2012). Entrainment is nearly $40 \%$ greater in the ship track vs the background. While the air above the inversion is quite moist (9.2 vs. $10 \mathrm{~g} \mathrm{~kg}^{-1}$ in the MBL), it is also potentially warmer, so cloud water evaporation due to entrainment warming may promote the in-cloud LWP decrease, consis- 

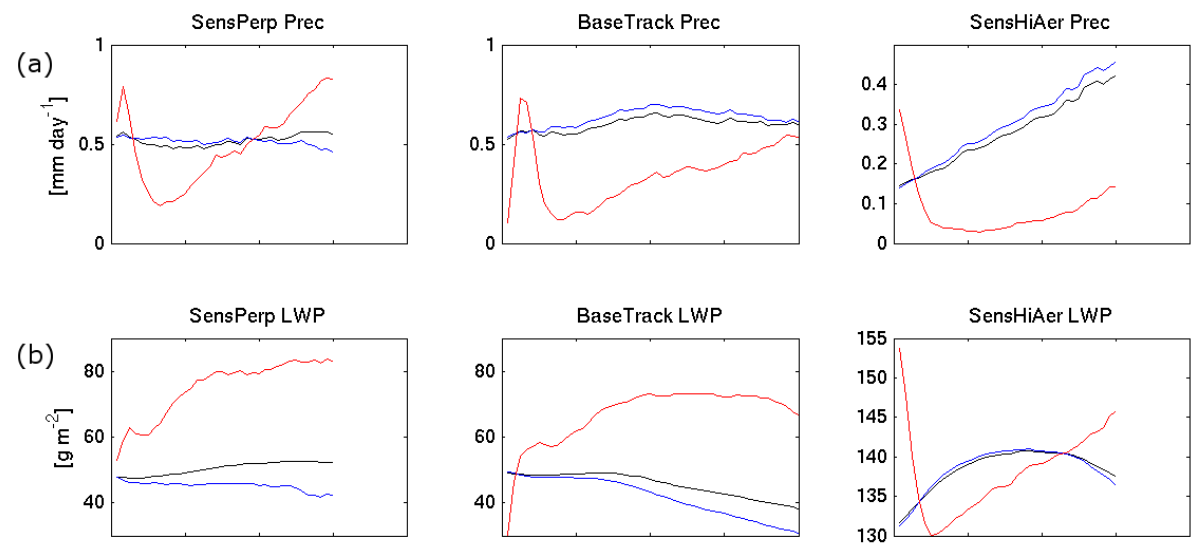

(c)
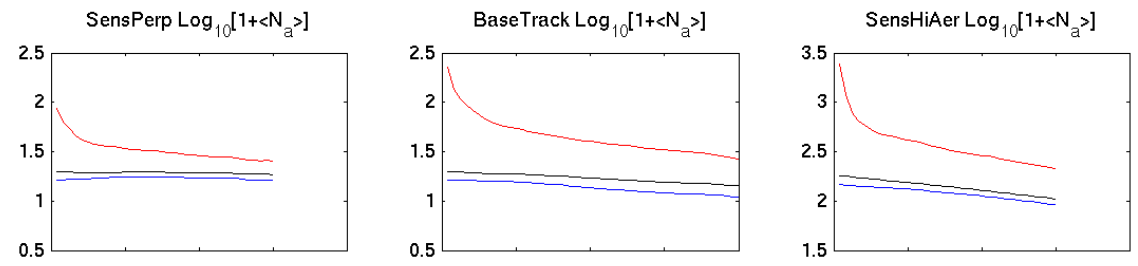

(d)
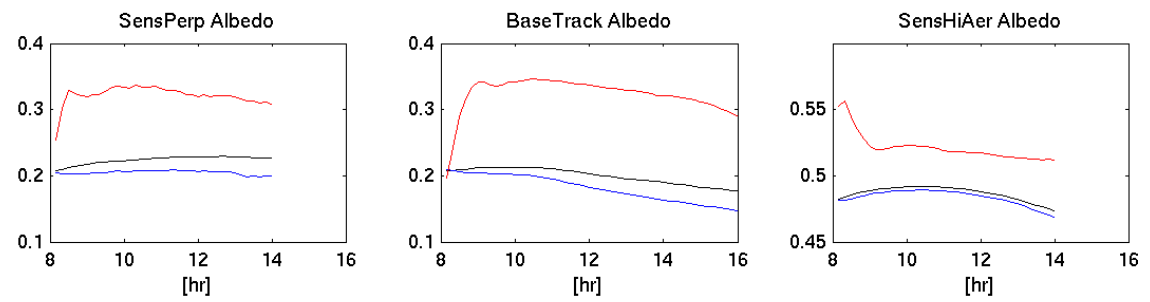

Figure 15. Track (red line), background (blue line), and domain (black line) averaged time series for runs SensPerp (first column), BaseTrack (second column), and SensHiAer (third column). Plotted are (a) surface precipitation rate, (b) LWP, (c) $\left\langle N_{\mathrm{a}}\right\rangle$, and (d) albedo.

tent with results of Ackerman et al. (2004), Bretherton et al. (2007), and Wood (2007). Alternatively, it is possible that this LWP difference reflects changing in-track contributions from high-LWP updrafts and low-LWP downdrafts of the circulation as the track spreads. The smooth time evolution of the in-track and environmental LWP suggest that their difference is real, rather than an averaging artifact. Once the difference is established, the track and background LWPs reconverge over the next $4 \mathrm{~h}$ (seen in Fig. 15). While the LWP in both the track and background initially increase at a similar rate during hour 9 due to continued cloud deepening, cloudaerosol feedbacks in the background allow for an increasing precipitation rate, arresting the LWP increase and leading to net loss from the background cloud by hour 12. By contrast, the elevated aerosol concentration in the track largely inhibits precipitation and allows for continued LWP gains, such that the track LWP exceeds that of the background after hour 12.5 .

Despite significant differences in boundary layer organization and background thermodynamic profile, SensHiAer evolves quite similarly to the high-aerosol case of Wang and
Feingold (2009), which is also in a nearly overcast and nonprecipitating cloud regime.

\subsection{Attribution of albedo response}

In this section, we estimate the contributions of the first and second aerosol indirect effects to the increase of TOA albedo $A$ in the ship track. To do this, we first estimate the "bulk" albedo $A_{\text {bulk }}$ of the cloud-containing layer, including both the fraction $f_{\text {cld }}$ of the columns within of that layer that contain cloud, and the clear columns in between. Since the cloudcontaining layer is thin, we neglect any clear-sky absorption or scattering within it, so its bulk albedo is due only to its cloudy columns:

$A_{\text {bulk }}=f_{\text {cld }} A_{\text {cld }}$

where $A_{\text {cld }}$ is the horizontal-average cloud albedo.

We use a simplified model for cloud albedo (e.g., Platnick and Twomey, 1994; Brenguier et al., 2000) as a function of cloud-mean $N_{\mathrm{d}}$ and in-cloud liquid water path $W_{\text {cld }}$ : 

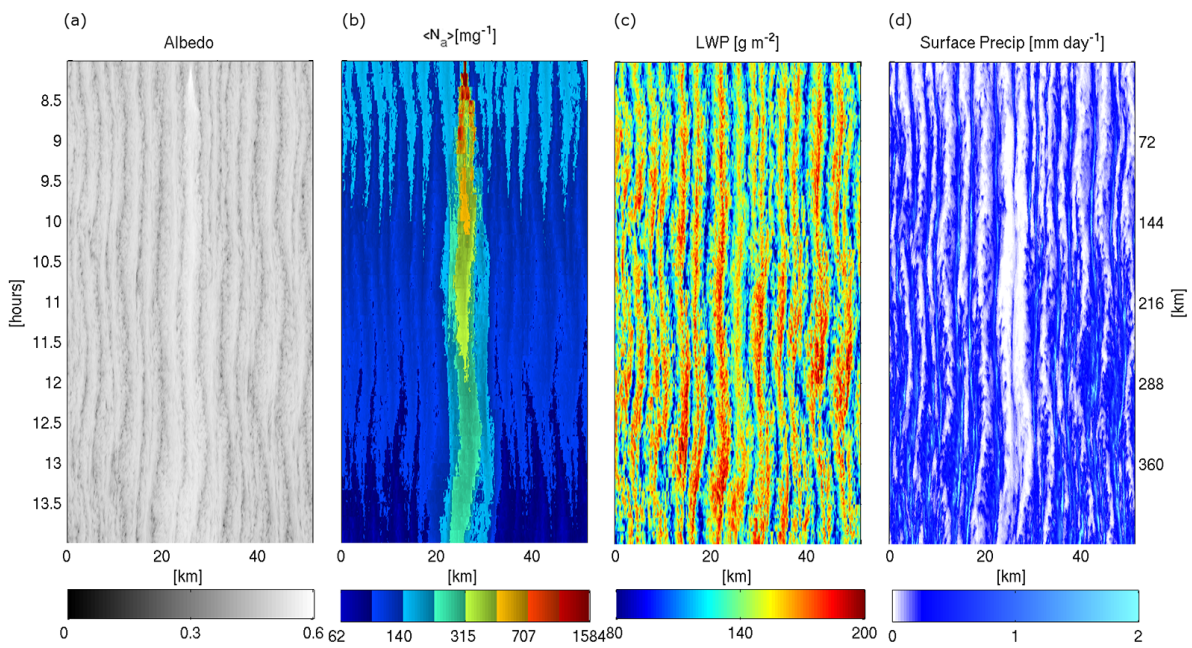

Figure 16. $x-t$ Hovmöller plot for run SensHiAer; panels as in Fig. 7.

$$
\begin{aligned}
A_{\text {cld }} & =\frac{(1-g) \tau}{2+(1-g) \tau} \\
\tau & =C_{1}\left(k N_{\mathrm{d}}\right)^{1 / 3} W_{\text {cld }}^{5 / 6},
\end{aligned}
$$

where

$C_{1}=0.0258\left(f_{\mathrm{ad}} \Gamma_{\mathrm{ad}}\right)^{-1 / 6}$.

In Eqs. (3) and (4), $g=0.85$ is the asymmetry factor for light scattering from a small spherical water droplet, $k=0.8$ is a breadth parameter for the droplet size distribution, $f_{\text {ad }}$ is an assumed ratio of the liquid water content profile to its adiabatic value, set to 0.65 in the drizzly low-aerosol runs and 0.9 in the high-aerosol sensitivity case, and $\Gamma_{\text {ad }}=2 \times 10^{-6}$ is a representative rate of adiabatic increase for liquid water content with height, in units of $\mathrm{kg} \mathrm{kg}^{-1} \mathrm{~m}^{-1}$. Using Eqs. (2), (3) and (4), we can separately estimate $A_{\text {bulk }}$ for the track and environment at each time based on their respective mean values of cloud fraction, LWP and $N_{\mathrm{d}}$. Horizontal cloud heterogeneity and inaccuracies in the assumed vertical structure of the in-cloud liquid water profile in the cloud will lead to errors in these estimates of $A_{\text {bulk }}$.

We use an empirical fit to go from $A_{\text {bulk }}$ to TOA albedo $A$. While we did not store the radiative fluxes for each column of the LES at each time, we did store their domain-mean values, which we use for this fit. Let $\mathrm{SW}_{\downarrow}$ and $\mathrm{SW}_{\uparrow}$ denote the domain-mean downwelling and upwelling shortwave fluxes, and let superscripts ${ }^{-}$and ${ }^{+}$denote fluxes at the cloud base and cloud top. To estimate the bulk albedo from the cloud base and cloud top fluxes, we must consider shortwave radiation impinging on the cloud from below as well as above. We neglect cloud-layer absorption, so a fraction $1-A_{\text {bulk }}$ of the upwelling shortwave radiation at cloud base exits through the cloud top, while by definition a fraction $A_{\text {bulk }}$ of the downwelling shortwave radiation at the top of the cloud layer is also reflected upward. After minor algebra, this implies that

$$
A_{\text {bulk }}=\frac{\mathrm{SW}_{\uparrow}^{+}-\mathrm{SW}_{\uparrow}^{-}}{\mathrm{SW}_{\downarrow}^{+}-\mathrm{SW}_{\uparrow}^{-}} .
$$

The cloud layer base and top are defined as the bottom and top model levels where domain-mean cloud fraction exceeds 0.05 . A scatterplot of domain-mean $A_{\text {bulk }}$ vs. $A$ including all output times from both the control and high-aerosol simulations yielded an accurate linear fit,

$A=0.69 A_{\text {bulk }}+0.07$,

which we also use separately for the track and environmental regions. Together with Eqs. (2), (3) and (4), (6) allows the LES TOA albedo to be predicted from the cloud fraction, LWP and $N_{\mathrm{d}}$, both inside and outside the track. The empirically determined intercept, 0.07 , which should be the clear-sky albedo, is reassuringly similar to the ocean surface albedo of 0.08 .

The top panels of Fig. 17 show the track and background values for $A$ derived from the LES-predicted radiative fluxes and the simplified model in each simulation. The simplified model predicts the evolution of the track and background albedos, and their difference, reasonably accurately, so is useful for decomposing their albedo difference into component contributions.

An approximate linearized decomposition of the response of $A_{\text {bulk }}$ into changes due to $N_{\mathrm{d}}, f_{\text {cld }}$ and $W_{\text {cld }}$ can be used to interpret the albedo response of the boundary layer to the ship track. It is derived from Eqs. (2), (3), and (4): 

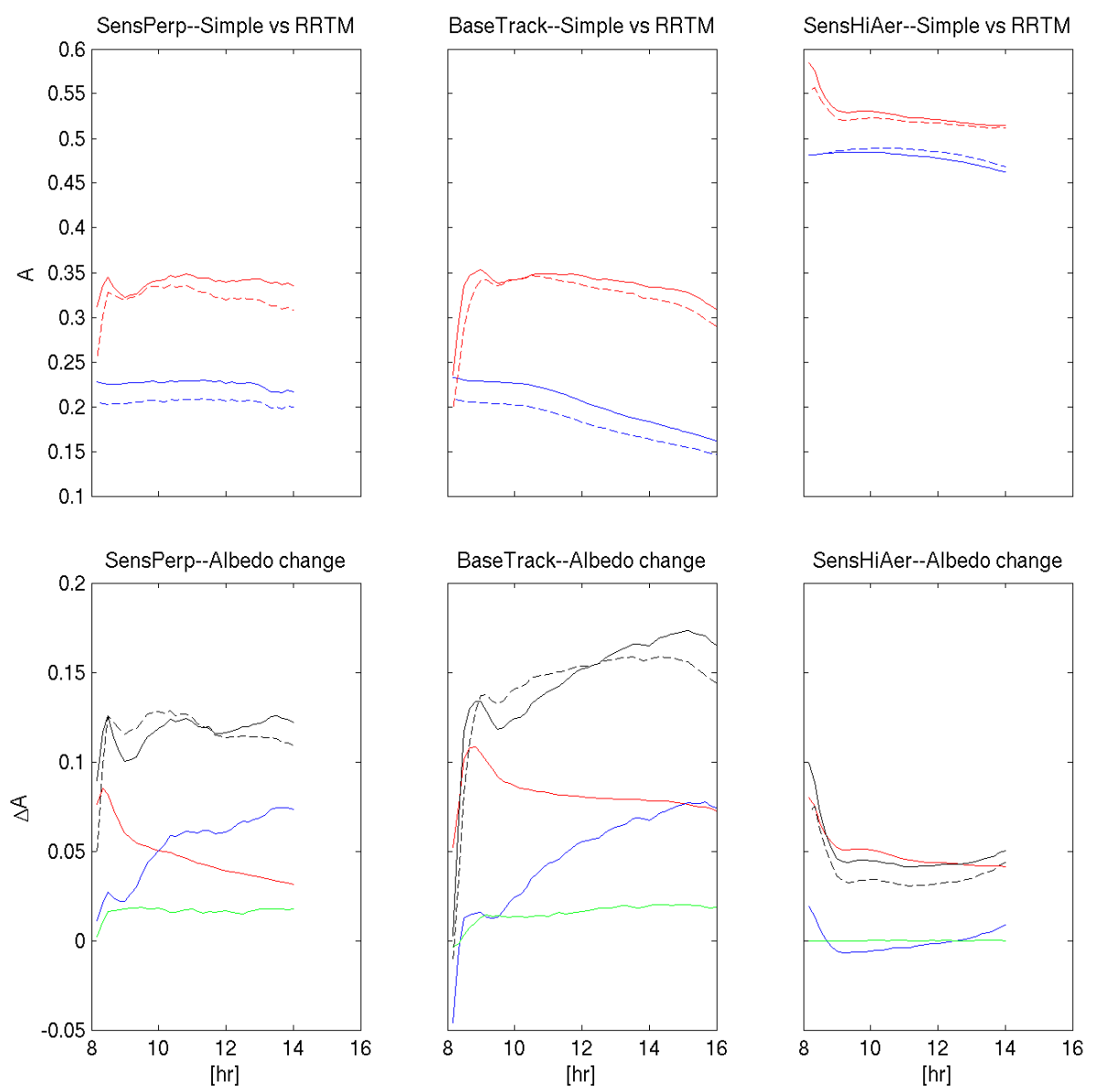

Figure 17. Top row: simple model (solid lines) and rapid radiative transfer model (RRTM; dashed lines) predicted $A$ for the track (red lines) and background (blue lines) in runs SensPerp (first column), BaseTrack (second column), and SensHiAer (third column). Bottom row: Albedo change due to changes of $N_{\mathrm{d}}$ (red lines), $W_{\text {cld }}$ (blue lines), and $f_{\mathrm{c}}$ (green lines), as well as total predicted change $\Delta A$ by the sum of terms (solid black lines) and derived from RRTM (dashed black lines). Runs are as in top row.

$$
\begin{aligned}
\Delta A_{\text {bulk }} & =\left(\frac{\partial A}{\partial \ln \tau}\right)_{\text {ref }}\left(\frac{\Delta \ln N_{\mathrm{d}}}{3}+\frac{5 \Delta \ln W_{\text {cld }}}{6}\right) \\
& +\Delta f_{\text {cld }} A_{\text {cld, ref }}, \quad \frac{\partial A}{\partial \ln \tau}=\frac{A_{\text {cld }}}{1-A_{\text {cld }}} .
\end{aligned}
$$

This is mapped via the linear fit (Eq. 6) to changes in $A$. We use the in-track conditions to define the reference state, which makes the linearization more accurate than using the background conditions.

The bottom panels of Fig. 17 apply this decomposition to our three ship track simulations. It captures the magnitude and evolution of the albedo difference predicted by the full idealized model and by the LES radiation code, validating the meaningfulness of this decomposition.

In run BaseTrack, Fig. 17 indicates the initial brightening of the track over the first hour is due primarily to increased $N_{\text {d }}$ (first aerosol indirect effect). Over the next several hours, however, the aerosol perturbation is laterally mixed and subject to various microphysical sinks, diminishing the $N_{\mathrm{d}}$ per- turbation. Simultaneously, precipitation suppression in the track induces a steady increase in $\Delta W_{\text {cld }}$. By the time the simulation ends at hour 16, the albedo contributions of enhanced $N_{\mathrm{d}}$ and LWP are comparable and when the cloud fraction enhancement in the track is also considered, second indirect effects are more significant to the track albedo perturbation than the first indirect effect. This pattern is repeated in run SensPerp, but here the LWP contribution becomes more rapidly significant.

In contrast, the albedo response of Run SensHiAer is dominated over the entire simulation by the first indirect effect, and the slight decrease of LWP within the track leads to a weakly negative second indirect effect during part of the simulation. In cases with a drier free-troposphere in which enhanced entrainment in the track may lead to a more pronounced decrease of LWP, the albedo in the track can actually be reduced compared to the environment (Chen et al., 2012). Cloud cover is not an important contributor to the second indirect effect in this case, since it remains nearly $100 \%$ both inside and outside the track. 
The importance of the second aerosol indirect effect in later stages of the SensPerp and BaseTrack runs indicates the need to simulate cloud macrophysical responses to aerosol. Similarly, run SensHiAer show that even in a very shallow cloud-topped boundary layer topped by a humid free troposphere, the second indirect effect need not be positive. Suppression of cloud surrounding the track in the simulations of Wang and Feingold (2009) is another form of negative second indirect effect which does not occur in our simulations due to the different environment. The range of possible effects poses a challenge for parameterization of cloud-aerosol interactions.

\section{Ship tracks and aerosol-cloud regimes}

Rosenfeld et al. (2006) suggested that closed cell, open cell, and collapsed boundary layer organizations exemplified aerosol-cloud regimes, where the availability of CCN would control boundary layer dynamics via precipitation and feedbacks on turbulence and cloud macrophysical structure, which in turn would modulate the CCN. They proposed that the boundary layer could naturally evolve via cloud-aerosolprecipitation interactions from closed cells to open cells, followed by transition to a collapsed state, but that strong injections of aerosol, such as from ship exhaust, could then reverse the process. Berner et al. (2013) explored the theme of aerosol-cloud regimes using LES, supporting the idea that closed cells, open cells, and collapsed boundary layers are "regimes" in the sense that under steady large-scale forcing, they evolve slowly with little qualitative change in structure over periods of days, with comparatively rapid transitions occasionally occurring between regimes. Do the Type 1 ship tracks simulated in the present work constitute a regime shift from a collapsing state back towards closed cell organization?

A framing of this question appropriate for our simulations is to ask whether, despite horizontal turbulent dilution, the mean microphysical and macrophysical properties within the track keep diverging from the background for an extended period, promoting a long track lifetime. Figure 15 shows that this is not the case; in BaseTrack, the track-mean cloud and aerosol properties are tending toward the background properties; since runs SensPerp and SensHiAer end at hour 14, the cloud properties have not evolved as much as in BaseTrack, but the approach of aerosol concentration toward the background suggests that cloud properties will eventually follow suit. With free-tropospheric aerosol, it is conceivable that a strong positive aerosol-entrainment feedback could amplify the in-track aerosol and cloud perturbations and foster a much more prominent and long-lived track. Indeed, the west part of Fig. 1 shows several prominent ship tracks in which the in-track cloud albedo remains high well downwind of the track head, despite substantial broadening of the track.

\section{Conclusions}

In this study, we have for the first time compared an LES with a coupled bulk aerosol scheme to a well-observed ship track. We simulated the Sanko Peace ship track from the 1994 MAST field campaign. The track formed in a shallow, low-aerosol boundary layer under high winds. We used a Lagrangian approach, simulating at high resolution a region around the track which evolves with time, corresponding to increasing downstream distance from the ship. Overall, the baseline simulation is quite successful. It compares well to important observed features, including prominent roll organization and microphysical characteristics of the ambient boundary layer, the magnitude of the cloud droplet number enhancement and albedo increase within the track, and the suppression of drizzle.

There are some discrepancies between simulation and observations, including the simulated ambient cloud being more broken than observed, the track being too narrow for its downstream distance from the source, less deepening of the simulated cloud tops in the track, a stronger and more single-layered temperature inversion compared to the observations, and apparently excessive aerosol in the shear-driven mixing layer just above the cloud top. These discrepancies are likely due to some combination of biases in the forcings used to drive the LES and in the aerosol source strength, better alignment of the simulated track along the wind than observed, and possible deficiencies in model physics.

The aerosol concentration in the simulated tracks evolves mainly by lateral dilution (at a rate sensitive to the orientation of the ship to the wind) as the tracks broaden. The winddriven surface aerosol source is countered by losses mainly due to accretion (which increases with time in the track as the in-track LWP increases) and cloud scavenging of interstitial aerosol (reduced within the track).

Liquid water path is enhanced in the Type 1 tracks, even though they also enhance entrainment of warmer air from aloft. For the simulated Type 2 ship track in a high-aerosol environment, entrainment is again enhanced, and depresses LWP below the background mean for $3.5 \mathrm{~h}$ until the surrounding cloud layer thickens and begins to drizzle, perhaps eventually leading to a transition to a Type 1 behavior.

In our simulated Type 1 tracks, albedo response is initially dominated by the first indirect effect. The second indirect effect becomes increasingly important over time and is responsible for the majority of the albedo perturbation by the end of the simulation. Our sensitivity study of a Type 2 track is dominated by the first indirect effect for the entirety of the $6 \mathrm{~h}$ run, with a negative second indirect effect for half of that time. Comprehensive ship track observations in a wider range of environments could be used to further test how well the quantitative details of aerosol-cloud interaction are represented by current aerosol models coupled to LES, or other types of process models. 


\section{The Supplement related to this article is available online at doi:10.5194/acp-15-5851-2015-supplement.}

Acknowledgements. Thanks to Marat Khairoutdinov of Stony Brook University for maintaining and providing SAM for use in this study, and to Peter Blossey at University of Washington (UW) for assistance with debugging model modifications. Simon Osborne of the UKMO kindly provided the C-130 data from the Sanko Peace case. Helpful conversations with Tom Ackerman and Bryce Harrop improved the manuscript. We would like to gratefully acknowledge support from National Science Foundation (NSF) grants ATM-0745702 and AGS-1242639, the University of Washington College of the Environment Geoengineering Initiative, as well as high-performance computing support from Yellowstone (ark:/85065/d7wd3xhc) provided by NCAR's Computational and Information Systems Laboratory, sponsored by the National Science Foundation.

Edited by: C. Hoose

\section{References}

Abdul-Razzak, H. and Ghan, S. J.: A parameterization of aerosol activation: 2. Multiple aerosol types, J. Geophys. Res., 105, 68376844, doi:10.1029/1999JD901161, 2000.

Ackerman, A. S., Toon, O. B., and Hobbs, P. V.: Dissipation of marine stratiform clouds and collapse of the marine boundary layer due to the depletion of cloud condensation nuclei by clouds, Science, 262, 226-229, doi:10.1126/science.262.5131.226, 1993.

Ackerman, A. S., Toon, O. B., and Hobbs, P. V.: Numerical modeling of ship tracks produced by injections of cloud condensation nuclei into marine stratiform clouds, J. Geophys. Res., 100, 7121-7133, doi:10.1029/95JD00026, 1995.

Ackerman, A. S., Kirkpatrick, M. P., Stevens, D. E., and Toon, O. B.: The impact of humidity above stratiform clouds on indirect aerosol climate forcing, Nature, 432, 1014-1017, doi:10.1038/nature03174, 2004.

Albrecht, B. A.: Aerosols, Cloud Microphysics, and Fractional Cloudiness, Science, 245, 1227-1230, doi:10.1126/science.245.4923.1227, 1989.

Berner, A. H., Bretherton, C. S., Wood, R., and Muhlbauer, A.: Marine boundary layer cloud regimes and POC formation in a CRM coupled to a bulk aerosol scheme, Atmos. Chem. Phys., 13, 12549-12572, doi:10.5194/acp-13-12549-2013, 2013.

Blossey, P. N. and Durran, D. R.: Selective monotonicity preservation in scalar advection, J. Comput. Phys., 227, 5160-5183, doi:10.1016/j.jcp.2008.01.043, 2008.

Brenguier, J.-L., Pawlowska, H., Schüller, L., Preusker, R., Fischer, J., and Fouquart, Y.: Radiative Properties of Boundary Layer Clouds: Droplet Effective Radius versus Number Concentration, J. Atmos. Sci., 57, 803-821, doi:10.1175/15200469(2000)057<0803:RPOBLC>2.0.CO;2, 2000.

Bretherton, C. S., Blossey, P. N., and Uchida, J.: Cloud droplet sedimentation, entrainment efficiency, and subtropical stratocumulus albedo, Geophys. Res. Lett., 34, L03813, doi:10.1029/2006GL027648, 2007.
Chen, Y.-C., Christensen, M. W., Xue, L., Sorooshian, A., Stephens, G. L., Rasmussen, R. M., and Seinfeld, J. H.: Occurrence of lower cloud albedo in ship tracks, Atmos. Chem. Phys., 12, 8223-8235, doi:10.5194/acp-12-8223-2012, 2012.

Chlond, A.: Three-dimensional simulation of cloud street development during a cold air outbreak, Bound.-Lay. Meteorol., 58, 161200, doi:10.1007/BF00120757, 1992.

Christensen, M. W. and Stephens, G. L.: Microphysical and macrophysical responses of marine stratocumulus polluted by underlying ships: Evidence of cloud deepening, J. Geophys. Res., 116, D03201, doi:10.1029/2010JD014638, 2011.

Christensen, M. W. and Stephens, G. L.: Microphysical and macrophysical responses of marine stratocumulus polluted by underlying ships: 2. Impacts of haze on precipitating clouds, J. Geophys. Res., 117, D11203, doi:10.1029/2011JD017125, 2012.

Clarke, A. D., Owens, S. R., and Zhou, J.: An ultrafine sea-salt flux from breaking waves: Implications for cloud condensation nuclei in the remote marine atmosphere, J. Geophys. Res., 111, 1-14, doi:10.1029/2005JD006565, 2006.

Coakley, J. A. and Walsh, C. D.: Limits to the Aerosol Indirect Radiative Effect Derived from Observations of Ship Tracks, J. Atmos. Sci., 59, 668-680, doi:10.1175/15200469(2002)059<0668:LTTAIR>2.0.CO;2, 2002.

Coakley, J. A, Bernstein, R. L., and Durkee, P. A.: Effect of shipstack effluents on cloud reflectivity, Science, 237, 1020-1022, doi:10.1126/science.237.4818.1020, 1987.

Conover, J. H.: Anomalous Cloud Lines, J. Atmos. Sci., 23, 778785, doi:10.1175/1520-0469(1966)023<0778:ACL>2.0.CO;2, 1966.

Deardorff, J.: Stratocumulus-capped mixed layers derived from a three-dimensional model, Bound.-Lay. Meteorol., 18, 495-527, 1980.

Dee, D. P., Uppala, S. M., Simmons, A. J., Berrisford, P., Poli, P., Kobayashi, S., Andrae, U., Balmaseda, M. A., Balsamo, G., Bauer, P., Bechtold, P., Beljaars, A. C. M., van de Berg, L., Bidlot, J., Bormann, N., Delsol, C., Dragani, R., Fuentes, M., Geer, A. J., Haimberger, L., Healy, S. B., Hersbach, H., Hólm, E. V., Isaksen, L., Kållberg, P., Köhler, M., Matricardi, M., McNally, A. P., Monge-Sanz, B. M., Morcrette, J.-J., Park, B.-K., Peubey, C., de Rosnay, P., Tavolato, C., Thépaut, J.-N. and Vitart, F.: The ERA-Interim reanalysis: configuration and performance of the data assimilation system, Q. J. Roy. Meteor. Soc., 137, 553-597, doi:10.1002/qj.828, 2011.

Durkee, P. A., Noone, K. J., and Bluth, R. T.: The Monterey Area Ship Track Experiment, J. Atmos. Sci., 57, 2523-2541, doi:10.1175/1520-0469(2000)057<2523:TMASTE>2.0.CO;2, 2000a.

Durkee, P. A., Chartier, R. E., Brown, A., Trehubenko, E. J., Rogerson, S. D., Skupniewicz, C., Nielsen, K. E., Platnick, S., and King, M. D.: Composite Ship Track Characteristics, J. Atmos. Sci., 57, 2542-2553, doi:10.1175/15200469(2000)057<2542:CSTC>2.0.CO;2, 2000b.

Etling, D. and Brown, R. A.: Roll vortices in the planetary boundary layer: A review. Bound.-Lay. Meteorol., 65, 215-248, doi:10.1007/BF00705527, 1993.

Faloona, I., Lenschow, D., Campos, T., Stevens, B., vanZanten, M., Blomquist, B., Thornton, D., Bandy, A., and Gerber, H.: Observations of entrainment in Eastern Pacific marine stratocumu- 
lus using three conserved scalars, J. Atmos. Sci, 62, 3268-3285, doi:10.1175/JAS3541.1, 2005.

Ferek, R. J., Hegg, D. A., Hobbs, P. V., Durkee, P., and Nielsen, K.: Measurements of ship-induced tracks in clouds off the Washington coast, J. Geophys. Res., 103, 23199-23206, doi:10.1029/98JD02121, 1998.

Glendening, J. W.: Lineal Eddy Features under Strong Shear Conditions, J. Atmos. Sci., 53, 3430-3449, doi:10.1175/15200469(1996)053<3430:LEFUSS>2.0.CO;2, 1996.

Hindman, E., Porch, W., Hudson, J., and Durkee, P.: Ship-produced cloud lines of 13 July 1991, Atmos. Environ., 28, 3393-3403, doi:10.1016/1352-2310(94)00171-G, 1994.

Hobbs, P. V., Garrett, T. J., Ferek, R. J., Strader, S. R., Hegg, D. A., Frick, G. M., Hoppel, W. A., Gasparovic, R. F., Russell, L. M., Johnson, D. W., O’Dowd, C., Durkee, P. A., Nielsen, K. E., and Innis, G.: Emissions from Ships with respect to Their Effects on Clouds, J. Atmos. Sci., 57, 2570-2590, doi:10.1175/15200469(2000)057<2570:EFSWRT>2.0.CO;2, 2000.

Khairoutdinov, M. F. and Kogan, Y. L.: A new cloud physics parameterization in a large-eddy simulation model of marine stratocumulus, Mon. Weather Rev., 128, 229-243, doi:10.1175/15200493(2000)128<0229:ANCPPI>2.0.CO;2, 2000.

Khairoutdinov, M. F. and Randall, D. A.: Cloud resolving modeling of the ARM summer 1997 IOP: Model formulation, results, uncertainties, and sensitivities, J. Atmos. Sci., 60, 607-625, 2003.

Liou, K. N. and Ou, S.C.: The role of cloud microphysical processes in climate: An assessment from a one-dimensional perspective, J. Geophys. Res., 94, 2156-2202, doi:10.1029/JD094iD06p08599, 1989.

Mlawer, E. J., Taubman, S. J., Brown, P. D., Iacono, M. J., and Clough, S. A.: Radiative transfer for inhomogeneous atmospheres: RRTM, a validated correlated-k model for the longwave, J. Geophys. Res., 102, 16663, doi:10.1029/97JD00237, 1997.

Morrison, H. and Grabowski, W. W.: Modeling supersaturation and subgrid-scale mixing with two-moment bulk warm microphysics, J. Atmos. Sci., 65, 792-812, doi:10.1175/2007JAS2374.1, 2008.

Morrison, H., Curry, J. A., and Khvorostyanov, V. I.: A new doublemoment microphysics parameterization for application in cloud and climate models. Part I: Description, J. Atmos. Sci., 62, 16651677, doi:10.1175/JAS3446.1, 2005.
Müller, G. and Chlond, A.: Three-dimensional numerical study of cell broadening during cold-air outbreaks. Bound.-Lay. Meteorol., 81, 289-323, doi:10.1007/BF02430333, 1996.

Platnick, S. and Twomey, S.: Determining the Susceptibility of Cloud Albedo to Changes in Droplet Concentration with the Advanced Very High Resolution Radiometer, J. Appl. Meteorol., 33, 334-347, doi:10.1175/15200450(1994)033<0334:DTSOCA>2.0.CO;2, 1994.

Radke, L. F., Coakley, J. A., and King, M. D.: Direct and remote sensing observations of the effects of ships on clouds., Science, 246, 1146-1149, doi:10.1126/science.246.4934.1146, 1989.

Rosenfeld, D., Kaufman, Y. J., and Koren, I.: Switching cloud cover and dynamical regimes from open to closed Benard cells in response to the suppression of precipitation by aerosols, Atmos. Chem. Phys., 6, 2503-2511, doi:10.5194/acp-6-2503-2006, 2006.

Stevens, B. and Feingold, G.: Untangling aerosol effects on clouds and precipitation in a buffered system, Nature, 461, 607-613, doi:10.1038/nature08281, 2009.

Taylor, J. P. and Ackerman, A. S.: A case-study of pronounced perturbations to cloud properties and boundary-layer dynamics due to aerosol emissions, Q. J. Roy. Meteor. Soc., 125, 2643-2661, doi:10.1002/qj.49712555915, 1999.

Twomey, S.: The influence of pollution on the shortwave albedo of clouds, J. Atmos. Sci., 34, 1149-1152, 1977.

Wang, H. and Feingold, G.: Modeling mesoscale cellular structures and drizzle in marine stratocumulus. Part II: The microphysics and dynamics of the boundary region between open and closed cells, J. Atmos. Sci., 66, 3257-3275, 2009.

Wang, H., Rasch, P. J., and Feingold, G.: Manipulating marine stratocumulus cloud amount and albedo: a process-modelling study of aerosol-cloud-precipitation interactions in response to injection of cloud condensation nuclei, Atmos. Chem. Phys., 11, 4237-4249, doi:10.5194/acp-11-4237-2011, 2011.

Wood, R.: Cancellation of Aerosol Indirect Effects in Marine Stratocumulus through Cloud Thinning, J. Atmos. Sci., 64, 2657 2669, doi:10.1175/JAS3942.1, 2007. 